Alonso, Fernando y Blázquez, Pablo. Carry trade y credit crunch en la economía española.

\title{
CARRY TRADE Y CREDIT CRUNCH EN LA ECONOMÍA ESPAÑOLA
}

\section{CARRY TRADE AND CREDIT CRUNCH IN THE SPANISH ECONOMY}

\author{
FERNANDO ALONSO \\ Departamento de Economía Aplicada I UCM \\ Instituto Complutense de Estudios Internacionales (ICEI) \\ falonsog@ucm.es \\ PABLO BLÁZQUEZ \\ Departamento de Economía Aplicada I UCM \\ Investigador del Instituto Complutense de Estudios Internacionales (ICEI) \\ pabblazq@ucm.es \\ Fecha de recepción: noviembre de 2013 \\ Fecha de aceptación: diciembre de 2013
}

\begin{abstract}
RESUMEN
El trabajo presenta algunos factores que han causado la restricción crediticia a las empresas y al consumo durante la etapa de crisis que vive aún hoy la economía española. Analiza las claves que han desembocado en esta situación como son las políticas aplicadas antes y durante la crisis por los Bancos Centrales, la distribución sectorial del crédito y el uso que del mismo han hecho los bancos comerciales en sus políticas de riesgo y liquidez. Los datos analizados vinculan la situación a dos fenómenos que tienen una clara integración en la actual situación del sistema financiero en España: el "carry trade" o uso del crédito a los bancos en la adquisición de deuda pública ha llevado al "credit crunch" con niveles de crédito muy por debajo de los existentes en cualquier otro país de la OCDE resultado del comportamiento de la banca comercial en el mecanismo de transmisión de la política monetaria.
\end{abstract}

PALABRAS CLAVE: crédito, política monetaria, credit crunch, carry trade, trading.

\begin{abstract}
This paper presents some factors which contribute and originate the current credit restrictions to companies and consumption during the crisis phase that have affected the Spanish economy is now experiencing. It analyzes key questions that lead to the current situation as policies applied by Central Banks before and during the crisis period, sectorial distribution of the credit, and performance of credit in commercial banks in their risk and liquidity policies. The quantitative data shows a clear link between two phenomena detected and integrated in the Spanish Financial System: the "carry trade" or the use of credit by the European Central Bank to buy great amounts of Public Debt caused the "credit crunch" with levels much lower than those existing in the other countries of OECD originated in base to the commercial banks behavior in their transmission role of the monetary policy.
\end{abstract}

Key words: credit, monetary policy, credit crunch, carry trade, trading.

JEL: F34, F36, G28.

Papeles de Europa

Vol. 26, Núm. 2 (2013): 64-92

http://dx.doi.org/10.5209/rev_PADE.2013.v26.n2.44184 
Alonso, Fernando y Blázquez, Pablo. Carry trade y credit crunch en la economía española.

\section{INTRODUCCIÓN}

Los mecanismos de transmisión de la política monetaria europea determinan que la liquidez del sistema se determina a través del crédito concedido a los bancos que, a través de la fijación de los tipos de interés y dada la velocidad de circulación monetaria, determinan los niveles de crecimiento de la M3, y esta a su vez cimenta la evolución del objetivo final que son los precios (Albentosa y Pacheco, 2009, Esteve García y Prats Albentosa, 2007). Esto es así desde que la política monetaria europea dio comienzo como proyecto común el 1 de enero de 1999 cuando el Banco Central Europeo se hizo cargo de las competencias en la materia monetaria y cambiaria de los once países que adoptaron el euro, y posteriormente las de otros seis países más, que sucesivamente se han adherido hasta el día de hoy ${ }^{1}$ (Bernardino y Alcázar, 2007). En los estatutos de constitución del BCE se estableció que el objetivo prioritario de la política monetaria iba a ser la estabilidad de precios, entendiendo esta, como el crecimiento del nivel de precios cercano al $2 \%$ con preferencia por el defecto más que por el exceso (Regato, 2000). El objetivo se ha mantenido y ha sido la principal preocupación aparente del BCE durante estos catorce años de existencia del euro, aunque la crisis económica que comenzara a finales de 2007 y que todavía continua le haya obligado a intervenir para garantizar la solvencia y vitalidad del sistema financiero (Díaz, 2011).

Para la consecución de dicho objetivo, el BCE fija arbitrariamente los tipos de interés con los que presta a los bancos, haciendo uso de su monopolio en cuanto a la creación de moneda. Al regular la liquidez, determina la cantidad de crédito a los bancos y el tipo de interés interbancario con el que se generan las expectativas de los inversores, repercutiendo en los tipos obtenidos por empresas y hogares para el normal funcionamiento de sus actividades de consumo e inversión. De esta forma tiene la capacidad de controlar la demanda de crédito, la oferta monetaria y por tanto la estabilidad de precios.

Desde el año 2007, inicio de la crisis que estamos sufriendo, las empresas españolas se han quejado en reiteradas ocasiones de las dificultades para obtener crédito como factor relevante en la profundización del escenario de crisis. La tasa de contracción del crédito desde finales de 2009 se puede atribuir tanto a factores de oferta como de demanda. Por el lado de la oferta se han endurecido las condiciones para acceder a la financiación bancaria. Acaso por la elevación de las tasas de morosidad, acaso por las necesidades de financiación de las Administraciones Públicas, acaso por las mayores necesidades de capital y restricción al riesgo del escenario bancario de Basilea III. El BCE elabora una encuesta a PYMEs y en ella se refleja que en España el porcentaje de créditos denegados es muy superior al de la media europea. Estos datos se corroboran en la encuesta sobre préstamos bancarios del Banco de España.

Nuestro objetivo es analizar la efectividad de los mecanismos de política monetaria aplicados por el BCE y su influencia sobre la restricción del crédito a empresas y familias, así como su influencia sobre la génesis y la gestión de la crisis económica. Para ello manejamos tres hipótesis: la primera sobre el uso que los bancos han

\footnotetext{
${ }^{1}$ En 1999 los países que adoptaron el euro fueron: Alemania, Austria, Bélgica, España, Finlandia, Francia, Italia, Irlanda, Luxemburgo, Países Bajos y Portugal. En 2001 se adhirió Grecia. En 2007 entró Eslovenia. En 2008 Chipre y Malta. En 2009 Eslovaquia y en 2011 Estonia.
} 
hecho de las inyecciones de liquidez del banco central y el uso abusivo del carry trade para mejorar sus balances y recursos propios; la segunda, sobre la influencia que Basilea III y los nuevos requerimientos de capital de alta calidad tier1 están teniendo sobre las políticas de gestión del riesgo de las carteras de crédito de las entidades financieras, siendo la primera causa del credit crunch; y tercero, el efecto que sobre la caída del crédito asignado al sector privado ha tenido la mayor demanda de crédito desde el sector público, que ha tenido que financiar cifras adicionales de déficit que van del $6.8 \%$ al $10,9 \%$ en lo que ha supuesto un claro efecto crowding out sobre el crédito al sector privado. Esto también ha alterado la composición en las asignaciones sectoriales del crédito para el caso de España desde la asunción de las competencias por parte del BCE. El factor crediticio, la selección de carteras de crédito, los modelos de gestión de riesgo crediticio, el empleo de los recursos monetarios por parte de los bancos y el trade off seguridadrentabilidad son importantes en el análisis de las causas y consecuencias del estrangulamiento crediticio en el sector empresarial y de consumo en España. Su estudio nos ayuda a comprender la evolución económica en distintos momentos del ciclo económico, la relevancia de los diferentes sectores de la economía y a la elaboración de prognosis que nos ayuden a vislumbrar tendencias. Primero, planteamos en el marco teórico los nexos a estudiar, a continuación supervisamos los mecanismos de transmisión de la política monetaria y la evolución de los pasivos de la banca española. Luego veremos la distribución sectorial del crédito. A continuación nos centraremos en la evolución y distribución del crédito desde el estallido de la crisis económica internacional en 2007. Por último, presentaremos un conjunto de conclusiones que el análisis realizado nos sugiere.

\section{MARCO TEÓRICO}

En los últimos años se han producido contracciones importantes del crédito (Comunidades Europeas, 1989) y elevaciones de la tasa de morosidad en España provocadas por las dificultades económicas vinculadas a la crisis y los modelos de gestión de riesgo y selección de carteras de crédito aplicadas por los bancos (De Miguel-Domínguez et al., 2003). La consecuencia ha sido un drástico desplome del crédito para empresas y familias (Aguado et al., 2013). Los balances bancarios, minados por las dotaciones y provisiones para insolvencias, han hecho el resto. Sólo el sector público, en un claro efecto crowding out sobre el crédito al sector privado (Broner et al., 2013), parece haber incrementado la cantidad de financiación, precisamente por la consideración que sobre el coeficiente de solvencia tienen los créditos concedidos al sector público en sus distintas instancias.

\subsection{El Carry Trade y la transmisión de la política monetaria}

Se denomina "carry trade" a la acción de financiarse o pedir prestado en activos de bajo rendimiento (o bajo coste) para colocar o invertir en instrumentos de alto rendimiento. Consiste por tanto en el trading a expensas del financiador para el aprovechamiento de los diferenciales de interés entre el factor de financiación y el factor de inversión. Habitualmente, esta estrategia está vinculada a los Hedge Funds que aprovechan riesgos estructurales para conseguir altas rentabilidades en posiciones cortas, asumiendo como propio el riesgo de cambio, al saltar 
Alonso, Fernando y Blázquez, Pablo. Carry trade y credit crunch en la economía española.

constantemente de unas monedas a otras (Cao et al., 2013; Lan et al., 2013; Anand et al., 2013).

El carry trade en sentido puro suele poner en valor la paridad de intereses cubiertos de las economías en las que aquellos países con divisas más débiles deben ofrecer para compensar su riesgo de tipo de cambio un mayor tipo de interés.

Tomemos como ejemplo lo que ocurre entre Estados Unidos y Japón. El país nipón tiene en las últimas décadas tipos de interés mucho más bajos que los de cualquier otra área. Por ello, la estrategia del carry trade consistiría en pedir prestado en yenes al $0.25 \%$ para colocarlo en países con rentabilidades más altas como Estados Unidos, Reino Unido o Australia. Este tipo de "arbitraje de tipos de interés y tipos de cambio" contribuye en sí mismo a igualar las rentabilidades, ya que aquellos activos más solicitados aumentarán su precio y reducirán su rentabilidad, y aquellas monedas más demandadas para invertir se encarecerán reduciendo el rendimiento global de la operación. Con esta estrategia se reduce el rendimiento del bono americano y se debilita al yen, apreciando al dólar. Todas estas operaciones se basan en grandes nominales y pequeños beneficios marginales que, acumulados al ser operaciones a corto, suelen ser la base del beneficio en los mercados monetarios. Si ante la situación el Banco de Japón sube tipos y la FED los baja para detener el arbitraje, desinflando rápidamente los incentivos hacia el carry trade.

En el caso de la Unión Monetaria, el factor "carry trade" ha tomado otros caminos. Ante la imposibilidad por parte del Banco Central Europeo de rescatar a las entidades bancarias por la oposición política dentro del Consejo Europeo hacia este tipo de prácticas (especialmente bajo el mandato de Trichet) y la ausencia de mecanismos de apoyo bancario definidas en sus propios estatutos, el BCE ha ideado una estrategia denominada política de «barra libre» (full allotment) instrumentada para cumplir con dos objetivos simultáneamente: el primero dotar de liquidez a las entidades bancarias con problemas asumiendo el coste del diferencial de financiación que aporta recursos para, mediante los beneficios no distribuidos, poder sanear sus balances y aumentar su core capital; en segundo lugar, ante la imposibilidad de intervenir en los mercados de deuda soberana para relajar las tensiones sobre las primas de riesgo, presta dinero para que otros lo hagan en su lugar (Alonso y Cendejas, 2012). Como resultado de esta política, la obtención de financiación «ilimitada» mediante las facilidades permanentes y las subastas de liquidez ocasionales del BCE en las que se pueden obtener recursos al $1 \%$ desde mayo de 2009, son un incentivo para que los bancos con más problemas lleven al límite sus demandas de liquidez para colocarlas posteriormente en deuda pública periférica a tipos mucho más altos, utilizada como soporte colateral al acudir a las subastas del BCE. Esto genera altos grados de apalancamiento financiero en las entidades y un coste por la emisión de los recursos temporales de liquidez para el BCE. El llamado carry trade constituye en sí mismo la principal amenaza para la activación del crédito, máxime comparando las rentabilidades de los bonos de los estados soberanos respecto a la del crédito privado con un $11 \%$ de tasa de morosidad.

Debido al uso y abuso que se ha producido en los últimos años de este instrumento de liquidez, el BCE ha puesto en marcha una serie de medidas restrictivas a la solicitud de crédito y a su destino, sin duda para mejorar la efectividad de la 
Alonso, Fernando y Blázquez, Pablo. Carry trade y credit crunch en la economía española.

transmisión de su política monetaria que usa el crédito al sistema bancario como principal actor en la evolución de su agregado monetario de referencia, la M3.

La estrategia puesta en marcha por Mario Draghi para ayudar a los bancos con problemas y a los Estados a financiar su deuda en lo que podría denominarse un rescate por la puerta de atrás se basa en proveer de dinero a los balances de los bancos de la zona euro mediante inyecciones de liquidez para que éstos compren la deuda soberana de los Estados. Estas inyecciones de liquidez han supuesto en sí mismas un punto de inflexión en la evolución de las primas de riesgo de los países periféricos. A pesar de la prohibición expresa que tiene en sus estatutos el BCE para la creación de dinero por su impacto sobre los precios, esta estrategia conlleva, en sí misma, una monetización indirecta -si bien con carácter temporal- del déficit (Comunidades Europeas, 1989).

Este mecanismo de inyección de liquidez, prácticamente ilimitado, se ha combinado con una mayor laxitud a la hora de aceptar como garantía activos de mayor nivel de riesgo, lo que permite un mayor aprovechamiento de los diferenciales de tipos para los bancos del eurosistema (Esteve y Prats, 2007, Díaz, 2011). Como cuadratura del círculo, el BCE considera que la deuda pública de los países soberanos pertenecientes al euro es plenamente segura y está exenta de riesgo de impago (Broner et al., 2013). Esto en la práctica supone que no computa en el coeficiente de solvencia de las entidades y no precisan por ello ningún tipo de provisión para insolvencia ni de capital propio inmovilizado como garantía de la inversión (Dunne et al.).

Los bancos europeos que más utilizan la estrategia del carry trade son Bankia, Sabadell, Popular y Bankinter, arbitrando con la subasta de liquidez del Banco Central Europeo (BCE) y la deuda a corto plazo. Estos bancos toman dinero al $1 \%$ a 36 meses a través del LTRO (Long Term Refinancing Operation) y lo colocan en deuda a corto plazo (con vencimientos a tres años) a un tipo más alto, obteniendo a medio plazo un diferencial de tipos positivos que engorda las cuentas de su balance y proporciona unos beneficios extraordinarios con los que proveen dotaciones que, en caso de no aplicarse, engrosan sus recursos propios, mejorando su solvencia y sus ratios de cara a Basilea III. Este arbitraje será especialmente beneficioso sobre todo para los bancos españoles con efectos inmediatos. Bankinter fue la entidad europea que más impacto favorable ha tenido en sus ganancias el pasado año, con casi un 30\% sobre el total de su beneficio, mientras para 2012 Bankia, Sabadell y Popular se beneficiarán de más de un $50 \%$ en sus resultados. También hay bancos italianos como UBI, Monte dei Paschi Siena y Unicredito, aunque todos por debajo del $20 \%$. Por debajo de estos, ya no aparece ninguna entidad cuyos beneficios se vayan a ver impactados favorablemente en más de un $10 \%$ por este carry trade (Barclays, 2013, Dunne et al., Krishnamurthy y Nagel).

HIPÓTESIS 1: Ante la imposibilidad política de rescatar a los bancos en apuros, el $\mathrm{BCE}$ ha llevado una política de emisiones transitorias de liquidez que han permitido, mediante el carry trade mejorar los balances de los bancos. 
Alonso, Fernando y Blázquez, Pablo. Carry trade y credit crunch en la economía española.

\subsection{Teoría de carteras de crédito, morosidad y credit crunch}

Según la teoría económica clásica, las fuerzas del mercado y la existencia de competencia libre, contribuyen a dejar fuera del mercado a aquellas empresas que se definen como ineficientes (Ricardo et al., 1819). Una institución bancaria con bajos niveles de eficiencia, altos niveles de insolvencia, o problemas de liquidez y morosidad, más temprano que tarde será expulsada del sistema por la aparición de otras más eficientes y con mejores ratios y efectividad (Maudos, 1996). Desde el punto de vista del regulador, la existencia de bancos con problemas de viabilidad supone una artera asignación de recursos, ya que las entidades ineficientes restan recursos a otras más productivas para el mismo capital dado. Lo deseable bajo esta situación sería un desmantelamiento de las más problemáticas mediante fórmulas voluntarias y ordenadas con sistemas de previsión que avancen situaciones de insolvencia en las entidades (Villarroya y de Guevara, 2008). El problema más importante al que debe enfrentarse el regulador es la posibilidad de un efecto dominó que se agudiza en función de los ratios de apalancamiento financiero de las entidades. Este riesgo se minimiza por la existencia del Fondo de Garantía de Depósitos y el cumplimiento de los coeficientes de solvencia (core capital y tier1) que facilitan el rescate de los ahorros en caso de insolvencia (Cabello y Urra, 2009, Ontiveros, 2000, Guillén, 2009, Aguado et al., 2013).

\section{Teoría de carteras de crédito}

La gestión del riesgo de crédito de una cartera bancaria se refiere a la estrategia implementada por el banco con el fin de evitar pérdidas por impago, costes asociados a la reclamación de la deuda y morosidad, así como el control de riesgos cuando no se reembolsan los préstamos y resto de inversiones. Para estandarizar estos riesgos se tienen en cuenta varios factores de la cartera de crédito:

1. La calidad de los activos: depende de la calificación global obtenida a partir de modelos de calificación de crédito. Estos procedimientos asignan cualidades de solvencia/riesgo a cada miembro de la cartera y es revisado para el análisis de los riesgos totales de la entidad anualmente por evaluadores y auditores externos. Para la valoración global del riesgo de la cartera se incluye la liquidez de los prestatarios, los ratios financieros, los fallidos, los de dudoso cobro, incobrables...

2. Diversidad: como en cualquier teoría de carteras, la diversidad y la atomización del riesgo hacen que las carteras se comporten como una distribución normal. Se trata de evitar una excesiva concentración que haga depender en exceso de un prestatario la garantía de la cartera. Asimismo, es recomendable diversificar geográficamente, en divisas, sectores. Se puede utilizar para ello la teoría de diversificación de carteras de Markowitz.

3. Flujo de efectivo: una de las claves es conseguir una alta tasa de rotación de los créditos, lo que requiere que el reembolso de los activos que componen una cartera deban coincidir con los fondos utilizados para la concesión de otros nuevos créditos. Es lo que se conoce como sincronización entre créditos. Ello se traduce en un flujo de efectivo estable.

Para la medición del riesgo de crédito se usan dos modelos: el método estándar y el método basado en rating internos (IRB Internal Rating-Based approach), este último con dos variantes, Básico (Foundation) y Avanzado (Advanced). 
Alonso, Fernando y Blázquez, Pablo. Carry trade y credit crunch en la economía española.

En el método IRB básico, a partir de los rating internos, se estiman la probabilidad de impago (PD, probability of default) y la exposición en caso impago (EAD, exposure at default) a un año para cada transacción. Para implementar el método IRB avanzado se requieren, adicionalmente, estimaciones independientes de pérdidas dado el impago (LGD, loss given default) y vencimientos (M, maturity). Los elementos que debe tener un sistema IRB son:

1. Una clasificación de la obligación según su exposición al riesgo de crédito (modelo de ratings internos) .

2. Componentes de riesgo. Para el modelo básico $P D$ y $E A D$, y para el modelo avanzado PD, EAD, LGD y $\mathrm{M}$.

3. Una función de ponderación de riesgo que utilice los componentes de riesgo para calcular las ponderaciones de riesgo

4. Un conjunto de requerimientos mínimos de elegibilidad para aplicar el enfoque IRB (por ejemplo, demostrar que los bancos mantienen el sistema de información necesario para implementar con precisión ese enfoque)

5. Revisión del supervisor del cumplimiento de los requerimientos mínimos

\section{Morosidad}

Se considera como moroso un crédito cuando se ha producido un retraso de tres meses en el pago de las cantidades a entregar (principal y/o intereses) por parte del deudor. Se trata de un concepto distinto al crédito fallido que es aquél que es considerado como incobrable por parte de la entidad. Es práctica habitual la venta de la cartera de estos últimos a entidades especializadas en su recobro a un descuento sustancial respecto su valor nominal como forma de sacarlos del balance y minimizar su impacto en la cuenta de resultados.

Los factores esenciales en la evaluación el análisis de la morosidad son el Nivel de morosidad y el Ratio de cobertura. El primero se determina a partir del porcentaje de créditos morosos respecto a los créditos vivos al final del periodo considerado. El total se obtiene mediante la agregación del anterior dato de morosidad del que se descuentan aquellos que pasan a formar parte de la cartera de fallidos, más los morosos incorporados durante el último periodo analizado. También se deducen aquellas recuperaciones en el periodo de cómputo. El ratio de cobertura es el nivel de provisiones que tiene el banco o caja sobre el total de créditos clasificados como morosos. Según la tipología utilizada por el Banco de España, estas provisiones pueden ser de dos tipos, las específicas, referidas a cubrir riesgos concretos, y las genéricas que suelen ser un porcentaje de la cartera total de crédito. Cuanto mayor es la provisión para morosidad, peor es el balance de resultados. En los últimos años, no es que los bancos españoles no hayan tenido beneficios, es que las provisiones para créditos de dudoso cobro o incobrables vivos han superado en cantidades provisionadas los beneficios obtenidos (BDE, 2000-2013, BDE, 20102013, Vega y BDE, 1992).

La morosidad del sistema bancario no es sino un reflejo de la situación del ciclo económico. Tiene una relación directa con la tasa de desempleo de la economía, con el incremento o decremento del PIB y con los niveles de consumo interno. Además se manifiesta con un cierto lap o retraso respecto de otras variables que pueden servir de indicadores adelantados. Un incremento de la tasa de desempleo en un $1 \%$ conlleva el incremento de la tasa de morosidad en casi un $0.9 \%$. 
Alonso, Fernando y Blázquez, Pablo. Carry trade y credit crunch en la economía española.

\section{Credit Crunch}

Un factor relevante en la gestión de recursos bancarios ha sido la actualización de la normativa bancaria a las exigencias de Basilea III $^{2}$ (Trillo del Pozo y Alonso, 2013). Estas novedades normativas vienen marcadas por el establecimiento de un porcentaje más elevado de capital de máxima calidad. La transcripción a la legislación española se hizo mediante el Real Decreto Ley 2/2011 que introdujo la noción de capital principal, y que un año más tarde ha sido modificado. La Ley 9/2012 (BOE 15 de noviembre) ha venido a modificar los requerimientos de capital principal que deben cumplir las entidades de crédito. El requisito era del $8 \%$ con carácter general y del $10 \%$ para las entidades con difícil acceso a los mercados. Desde el 1 de enero de 2013, los requisitos existentes son del $9 \%$ con carácter general. Este porcentaje se irá aumentando de forma progresiva en los próximos años. Los efectos que estas medidas tienen sobre la política monetaria son al menos dos: primero, reduce el dinero en circulación, contrayendo la M3 al reducirse, tanto la velocidad de circulación del dinero como la generación de dinero bancario, lo que constituye en sí mismo una contracción de la masa monetaria en circulación; segundo, reduce la cantidad disponible de crédito concedido por las entidades, especialmente aquellos créditos que más penalizan en el coeficiente de solvencia créditos personales, al consumo, a empresas- en contraposición a aquellos concedidos a organismos públicos, cuya penalización en dicho coeficiente es, en términos globales, mucho menor (Canal, 2001, Comunidades Europeas, 1989, Aguado et al., 2013, Climent Serrano, 2013, ECB, 2010-2013, Weekly, 2013).

Un elemento clave de la circular bancaria establece criterios sobre cuáles y en qué porcentaje computan los activos y pasivos bancarios, qué se verifica como core capital, requisitos de emisión, especialmente deuda subordinada y activos convertibles (Catarineu y Pérez, 2008). En este sentido, la recomendación del BCE es la de ajustar las exposiciones ponderadas por el riesgo para que las necesidades de capital que lo respalde nunca excedan el valor de la exposición, manteniendo así los ratios entre ambas magnitudes. En la circular ECB 7/2012 (BOE 11 de diciembre de 2012) se establece la frecuencia de los controles y la periodicidad con la que deben informar al BCE. El capital principal o "core capital" está constituido por el capital social de los bancos, cajas de ahorro (fondo fundacional en las cajas de ahorros y cuotas participativas) y cooperativas de crédito (aportaciones de capital de los socios). De este capital se excluyen las acciones sin voto, las primas de emisión desembolsadas, las participaciones representativas de los intereses minoritarios que correspondan a acciones ordinarias de las sociedades del grupo consolidable, los instrumentos computables suscritos por el FROB en el marco de su normativa reguladora y los instrumentos convertibles en acciones ordinarias, las cuotas participativas de las cajas de ahorros o las aportaciones al capital de las cooperativas de crédito, que el Banco de España califique como computables por cumplir con los requisitos exigidos para su cómputo como recursos propios básicos y por cumplir con las demás condiciones de emisión fijadas por la Autoridad Bancaria Europea. De los elementos anteriores deben deducirse los resultados negativos (incluidos los atribuidos a los socios minoritarios), los activos inmateriales y el $50 \%$ de ciertos activos, en particular los que pueden suponer un doble cómputo del capital dentro del sistema financiero. Adicionalmente, la Ley prevé que el Banco de

\footnotetext{
2 (Basel Committee on Banking Supervision) reformas de la regulación del capital y liquidez, septiembre de 2010 .
} 
Alonso, Fernando y Blázquez, Pablo. Carry trade y credit crunch en la economía española.

España pueda exigir el cumplimiento de un nivel de capital principal superior, en función de los resultados de ejercicios de resistencia que puedan hacerse para el conjunto del sistema. Asimismo, el Banco de España, en el marco de la revisión supervisora de la adecuación de capital, podrá exigir a las entidades o grupos citados contar con un exceso adicional de capital principal ${ }^{3}$.

Se utiliza un enfoque de cartera para medir el riesgo, clasificando los activos en cuatro categorías, en cada categoría la exposición es ponderada $(0 \%, 20 \%, 50 \%$, $100 \%$ ) según el tipo de deudor. Existe también una escala de consumos para las operaciones fuera de balance. La normativa de Basilea está basada en el modelo RAR (Risk Asset Ratio), según el cual las entidades han de mantener un capital mínimo del $8 \%$ sobre los activos ponderados por riesgo.

$$
R A R=\frac{R R \cdot P P}{\sum_{i=1}^{N} \alpha_{i} \cdot A_{i}}>=8 \%
$$

Donde: $R R \cdot P P=$ Recursos Propios; $\alpha i=$ coeficientes de ponderación de riesgo que toman valores de 0 a 100; $A i=$ valor del activo sometido al coeficiente.

Tabla 1: requisitos de Basilea II, ponderación, riesgo y cobertura

\begin{tabular}{|c|c|c|c|c|c|c|c|}
\hline BASILEA II & $A A A$ a $A A-$ & $A A+a A-$ & $\begin{array}{c}B B B+a \\
B B B-\end{array}$ & $B B+a B B-$ & $B+a B-$ & $\begin{array}{c}\text { Por debajo } \\
\text { de B- }\end{array}$ & $\begin{array}{c}\text { No } \\
\text { clasificados }\end{array}$ \\
\hline Soberano & $0 \%$ & $20 \%$ & $50 \%$ & $100 \%$ & $100 \%$ & $150 \%$ & $100 \%$ \\
\hline $\begin{array}{l}\text { Gobiernos Regionales y } \\
\text { Locales }\end{array}$ & \multicolumn{7}{|c|}{ Igual que la entidades de crédito } \\
\hline Empresas públicas & \multicolumn{7}{|c|}{ Igual que la entidades de crédito } \\
\hline $\begin{array}{l}\text { Entidades de crédito } \\
\text { Opción } 1\end{array}$ & $20 \%$ & $50 \%$ & $50 \%$ & $100 \%$ & $100 \%$ & $150 \%$ & $50 \%$ \\
\hline Opción 2 & $20 \%$ & $50 \%$ & $100 \%$ & $100 \%$ & $100 \%$ & $150 \%$ & $100 \%$ \\
\hline Empresas & $20 \%$ & $50 \%$ & $100 \%$ & $100 \%$ & $150 \%$ & $150 \%$ & $100 \%$ \\
\hline
\end{tabular}

Fuente: De Miguel-Domínguez et al., 2003

Basilea III reforma los porcentajes (mayor core capital exigido), eleva el riesgo y aumenta la cobertura de los activos bancarios, lo que resulta en una mayor necesidad de capital para cubrir los ratios de solvencia. A cambio, concede una mayor flexibilidad interna en la asignación de riesgos específicos en la cartera de crédito de las instituciones.

HIPÓTESIS 2: Basilea III ha provocado una gestión más conservadora de la cartera de crédito bancario, lo que unido a los mayores requerimientos de core capital para las entidades ha llevado a una situación de credit crunch.

\subsection{Efecto crowding out y financiación de la deuda pública}

El crowding out es un fenómeno habitual en los países desarrollados donde la demanda de crédito privada debe competir por captar recursos de los ahorradores

\footnotetext{
${ }^{3}$ Banco de España (Eurosistema) 16 de octubre de 2012 Análisis de los procedimientos supervisores del Banco de España y recomendaciones de reforma MoU FSPC - Informe de la Comisión Interna.
} 
Alonso, Fernando y Blázquez, Pablo. Carry trade y credit crunch en la economía española.

con la demanda de crédito pública necesaria para financiar el déficit y la deuda pública. Los elevados niveles de deuda existentes en países como Japón, Estados Unidos o Italia absorben una gran cantidad de recursos de crédito de las economías. El trade-off que se da entre la asignación de los recursos entre el sector público y privado se denomina crowding out, la expulsión del sector privado de la economía por parte del sector público. El Estado tiene que competir con las empresas por la captación del ahorro. En la medida que las necesidades de financiación del Estado son mayores o la oferta de crédito menor, conlleva una elevación de los tipos de interés y un encarecimiento del crédito que acaba por expulsar de la contienda a los demandantes privados de crédito por el coste de la financiación de la inversión de las empresas. El desplazamiento de la inversión privada se materializa en: alzas de los tipos de interés que hacen más difícil y costosa la financiación de las empresas; en el fomento de la concentración empresarial hacia monopolios y nacionalizaciones de empresas; una retroalimentación del sistema para generar más deuda pública elevando el umbral de rentabilidad de las emisiones privadas.

HIPÓTESIS 3: Las necesidades de financiación de las entidades públicas en una situación de restricción financiera, han presionado al alza los tipos efectivos de los créditos al sector empresas y consumo, reduciendo el volumen total de crédito concedido y elevando su coste.

\section{LA POLÍTICA MONETARIA DEL BCE Y EL CRÉDITO BANCARIO}

\subsection{Caracterización de la política monetaria}

Como ya se expuso de forma sucinta en la introducción, el objetivo de la política monetaria es la estabilidad de precios, establecida ésta en torno al $2 \%$ y siendo el indicador utilizado para su medición el Índice Armonizado de Precios al Consumo, tal y cómo se acordó en el Consejo de Gobierno del BCE en octubre de 1998. Para la consecución de este objetivo, se constituyó una estrategia de trabajo consistente en dos líneas de análisis sobre las cuales se toman las decisiones: análisis de coyuntura económica y el análisis monetario. Es en este último sobre el que se desarrollará nuestra investigación.

La teoría subyacente al análisis monetario del BCE consiste en la proposición de que la evolución de la inflación está intrínsecamente relacionada con el crecimiento de la cantidad de dinero (tomando como referencia el agregado monetario $\mathrm{M}^{4}$ ) en un horizonte de medio y largo plazo, dejando sintetizando los shocks externos ${ }^{5}$ en influencias cortoplacistas. Es decir, que en el corto plazo son estas perturbaciones externas las que marcan el ritmo de inflación dejando prácticamente sin efecto a las decisiones de política monetaria, aunque en la visión de medio y largo plazo la inflación depende de la cantidad de dinero. Ésta es la denominada teoría de la neutralidad del dinero que defiende que a medio y largo plazo el crecimiento económico se explica por variaciones de variables reales como la tecnología, el

\footnotetext{
${ }^{4}$ El agregado monetario M3 incluye: efectivo en circulación, depósitos a la vista, depósitos a plazo de hasta dos años, depósitos disponibles con preaviso de hasta tres meses, cesiones temporales, participaciones en fondos del mercado monetario y los valores distintos de acciones de hasta dos años.

${ }^{5}$ Los shocks externos que el BCE establece son principalmente: variaciones en las primas de riesgo, variaciones en el capital de los bancos, cambios en la economía mundial, cambios en la política fiscal y cambios en los precios de las materias primas.
} 
Alonso, Fernando y Blázquez, Pablo. Carry trade y credit crunch en la economía española.

crecimiento de la población o la productividad entre otras y no por variables monetarias, por lo que a medio y largo plazo aumentos de la cantidad de dinero por encima de lo deseado solo producen efectos inflacionistas. Partiendo de este postulado, el BCE estima que el crecimiento potencial de la economía de la Eurozona es del $2 \%$ y además puede ir acompasado con un leve descenso de la velocidad de circulación de M3. Sobre estos supuestos se considera que la velocidad de crecimiento anual de $M 3$ debe estar en torno al 4,5\% y 5,5\% para conseguir el objetivo de inflación del 2\% (Vilariño, 2001).

A continuación se exponen los datos sobre las variaciones del IAPC, de los tipos de interés y del agregado M3. Los gráficos nos muestran que desde la puesta en funcionamiento del euro en 1999 hasta la actualidad, no han estado en los órdenes previstos ni el agregado M3 (entre el $4,5 \%$ y el 5,5\%) ni tampoco se ha mantenido la inflación cercana -aunque por debajo- del 2\%. Entre 1999 y el último cuatrimestre del año 2000 los tipos de interés aumentaron del 3\% al 4,75\% con el objetivo de tratar de enfriar la burbuja tecnológica sin éxito significativo, ya que, durante ese mismo periodo M3 no paró de aumentar hasta un 11\% y el IAPC aumentó hasta el 3\%. Es decir, a pesar de los esfuerzos para mantener la inflación estable, la subida de tipos de interés no fue suficiente.

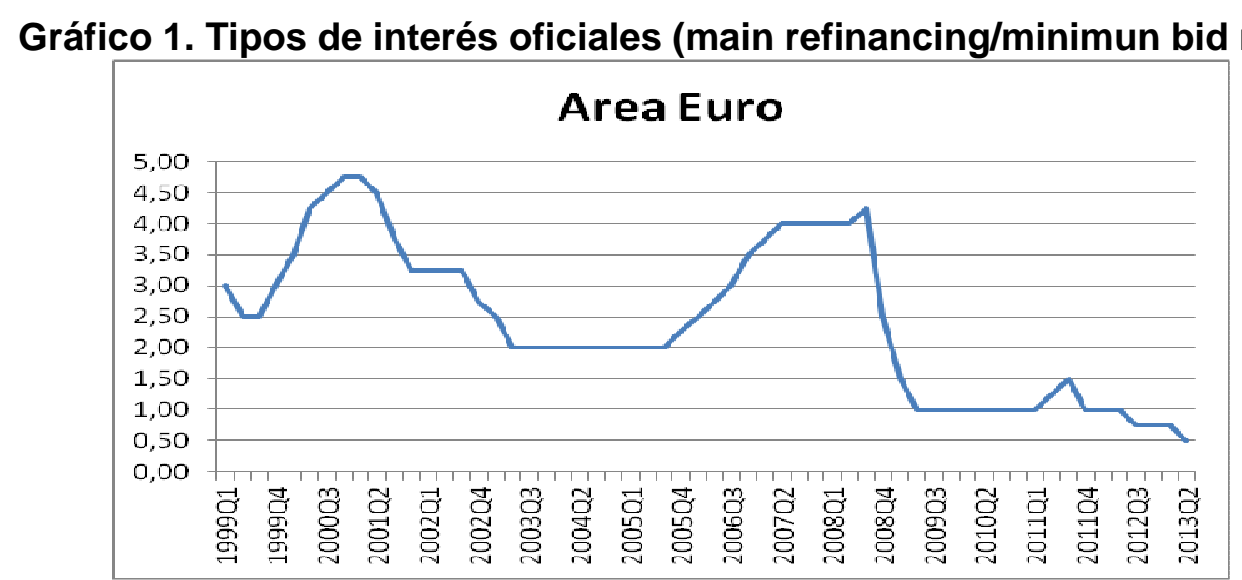

Elaboración propia. Fuente: Eurostat.

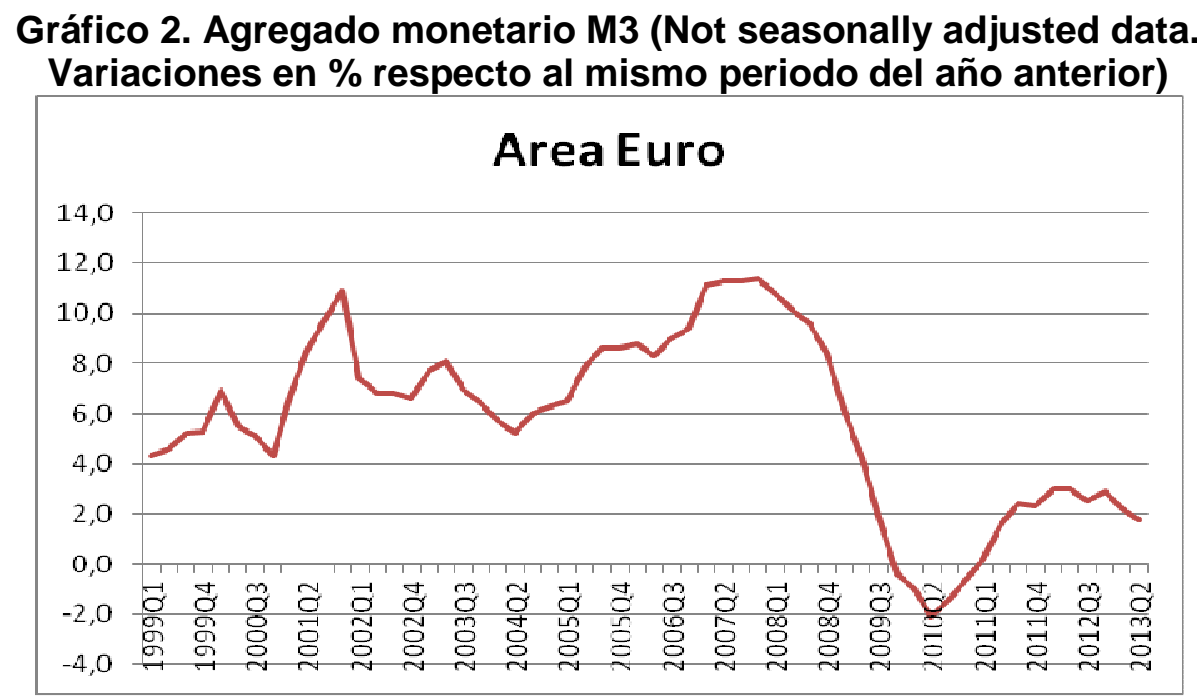

Elaboración propia. Fuente: Eurostat. 


\section{Gráfico 3. Índice Armonizado Precios al Consumo (Euro Area Overall index, Annual rate of change, neither seasonally nor working day adjusted)}

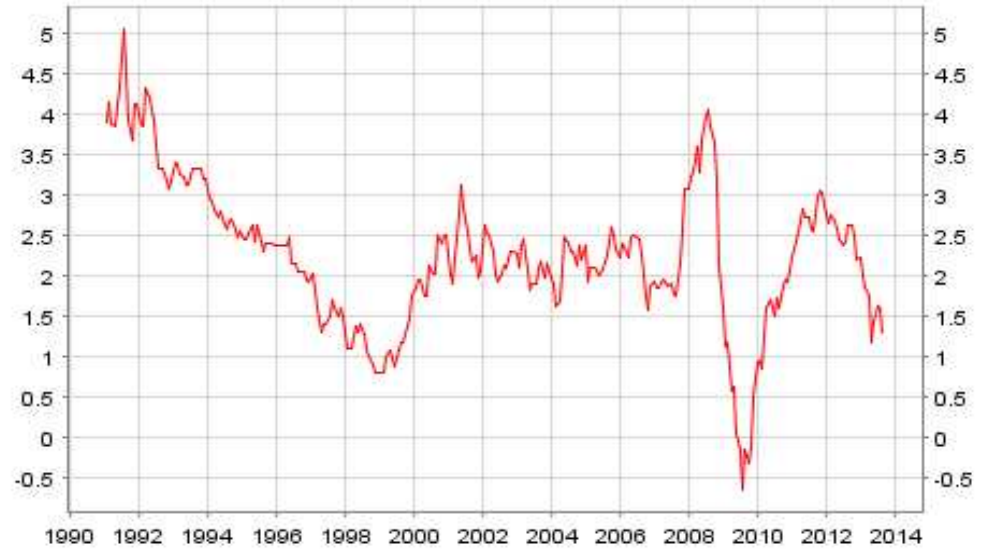

Fuente: Eurostat.

A partir de 2001, tras el estallido de la crisis que afectó a las principales economías occidentales, la política monetaria cambió de dirección: se redujeron los tipos de interés de forma rápida del 4,75\% a finales del año 2000 hasta el 3\% en 2001 y el 2\% en 2003 (Hein et al., 2012, Rodríguez et al., 2010). Esta bajada de tipos, además de rápida, fue sostenida en el tiempo hasta el tercer trimestre de 2005, cuando las burbujas inmobiliarias y financieras se extendían por la zona euro. Durante este periodo 2001-2005, la M3 se mantuvo contenida pero siempre entre el $6 \%$ y el $8 \%$ tras la reducción pronunciada motivada por la crisis (Guide, 2013, Guillén, 2009) (Chossudovsky y Marshall, 2010) ${ }^{6}$. En cuanto al IAPC, éste se mantuvo controlado aunque ligeramente por encima del $2 \%$ superando lo que el BCE considera como objetivo en sus estatutos. A partir de 2005 la burbuja financiera e inmobiliaria empezó a alimentarse, la demanda de dinero también escaló a niveles preocupantes llegando hasta el $10 \%$ en 2007 y casi el $12 \%$ en 2008 . El escenario alcista alcanzó el máximo en 2007, y se mantuvo hasta la caída de Lehman Brothers en septiembre de 2008, terremoto que mantuvo en vilo al sistema financiero global y lo puso al borde de la quiebra técnica. A partir de entonces los tipos bajan, la M3 cae en picado y los precios sufren grandes oscilaciones debido a los diferentes shocks que a partir de entonces ha sufrido la economía europea y mundial (Vilariño, 2001, Vilariño, 2009).

De los gráficos expuestos hay dos hechos sobre los cuales consideramos que debe hacerse una mención especial. El primero es la relación entre los tipos de interés y el agregado M3; resulta cuanto menos llamativo que la relación precio-cantidad haya sido positiva. Como si cuanto mayor fuera el precio (mayor tipo de interés) mayor fuera la cantidad demandada. Esta relación positiva resulta de gran interés pero no es el objeto de este trabajo su análisis. El segundo hecho a mencionar es el escaso efecto que el exceso de liquidez, medido por la M3, especialmente entre 2004 y 2007, tuvo en el IAPC. Este hecho se explica por el papel alcanzado por el euro a nivel internacional como moneda de reserva (De Grauwe, 2012, De Grauwe y Vanhaverbeke, 1993).

\footnotetext{
${ }^{6}$ Provocada por la crisis de las punto com (burbuja tecnológica) y los atentados del 11 de septiembre. 


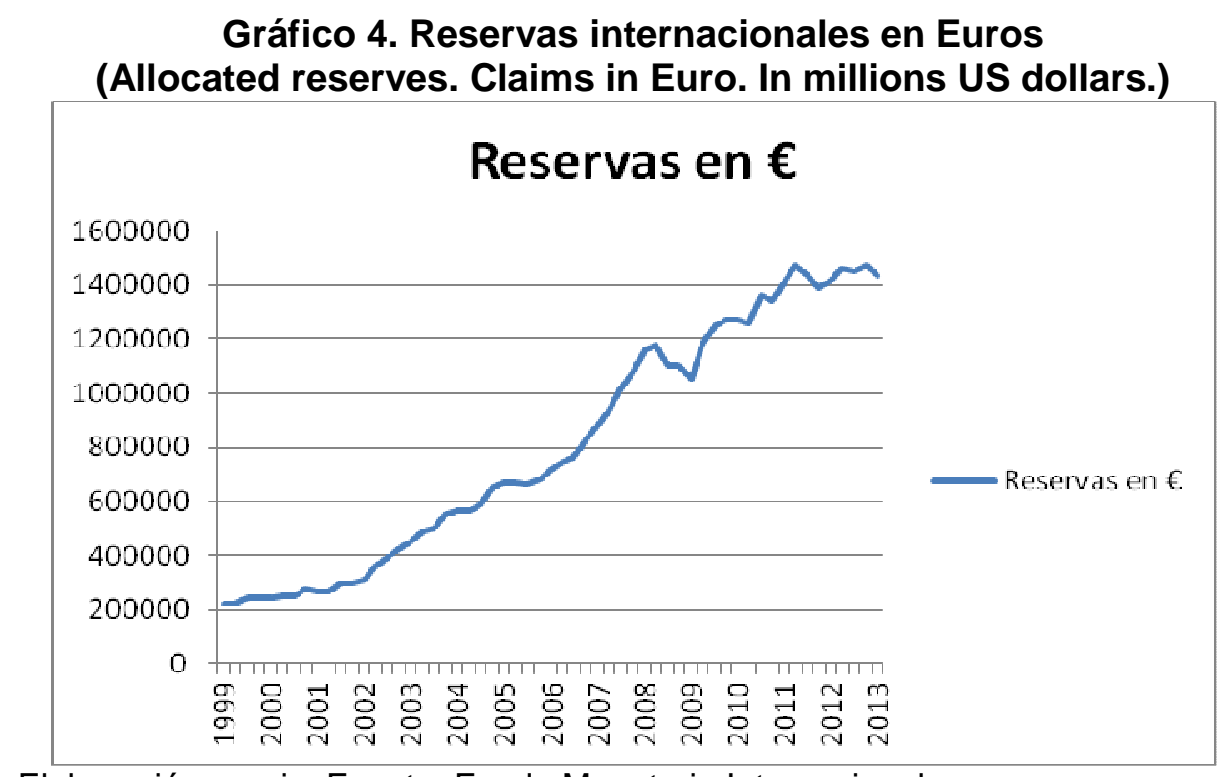

Elaboración propia. Fuente: Fondo Monetario Internacional.

Como muestra el gráfico 4, las reservas internacionales en euros han aumentado de forma continuada desde el año 1999, siendo especialmente acentuado el crecimiento entre el periodo mencionado 2004-2007. El euro, como moneda de reserva internacional, se ha posicionado dentro del sistema monetario internacional por delante del resto de monedas de reserva (la libra esterlina, el yen japonés, el franco suizo, el dólar australiano y el dólar canadiense) salvo del dólar, que mantiene su supremacía como moneda global. Esta aceptación internacional es la que ha permitido que el agregado monetario M3 haya aumentado de forma considerable por encima de lo establecido sin generar inflación.

\subsection{Mecanismo de transmisión y el papel del crédito bancario}

El mecanismo de transmisión de la política monetaria es el proceso mediante el cual el Banco Central Europeo influye en la economía real con sus decisiones de política monetaria, siendo el instrumento utilizado para ello los tipos de interés. Mediante la fijación arbitraria de los tipos de interés, gracias al monopolio que sustenta de la emisión de dinero, influye en los tipos del mercado monetario, es decir, en los tipos de interés de los fondos negociados a corto plazo y por tanto, en los tipos de interés de préstamos y depósitos. Al mismo tiempo, también afecta a las expectativas de inflación a medio y largo plazo, los tipos de cambio y los precios de los activos, lo que en su conjunto influye en las decisiones de los inversores y en la oferta y demanda de crédito (Andrés, 2003). En definitiva, mediante la fijación de los tipos de interés, interviene en las decisiones de ahorro e inversión de los agentes donde los bancos juegan el papel protagonista como intermediarios. Es en este sentido donde se muestra el papel vital que juega el crédito en la efectividad de la política monetaria y en la economía real al ser el principal impulsor de la inversión. Con el poder de persuasión en las expectativas, en las decisiones de ahorro-inversión y en el tipo de cambio, el BCE puede, en teoría, controlar las variaciones de los precios internos y de los precios de las importaciones, y por tanto, el nivel general de precios (Barclays, 2013).

Tal y como hemos visto en el gráfico 2, podríamos afirmar que ha tenido un carácter expansivo desde su puesta en funcionamiento. Aunque este carácter expansivo no 
Alonso, Fernando y Blázquez, Pablo. Carry trade y credit crunch en la economía española.

se ha materializado en una inflación elevada por el cada vez más afianzado papel del euro como moneda de reserva internacional. Empero, la eurozona está formada por economías que todavía sostienen profundas divergencias entre ellas en cuanto a estructura, productividad e historia. En el caso español, la entrada en el euro permitió el acceso a cantidades ingentes de capital con bajo coste, marcando un antes y un después desde la firma de la constitución de 1978 y los pactos de la Moncloa en 1979. Las entidades de depósito (bancos, cajas de ahorro y cooperativas de crédito) aprovecharon el nuevo entorno monetario presentado por el euro adquiriendo importantes cantidades de capital que fueron incrementando con el tiempo y trasladando vía créditos, con cada vez menores requisitos, a los agentes económicos. En definitiva, creciente y elevado apalancamiento del sector privado en su conjunto. A continuación se exponen una serie de gráficos con el objeto de mostrar la tendencia de apalancamiento $^{7}$ de las entidades de depósito en su conjunto, en especial, entre 1999 y 2007. En el gráfico 5 observamos la evolución de las Operaciones Principales de Financiación entre el BCE y las entidades españolas. Las OPF son operaciones temporales de inyección de liquidez de carácter regular, periodicidad semanal y vencimiento a una semana (de Grauwe, 2012).
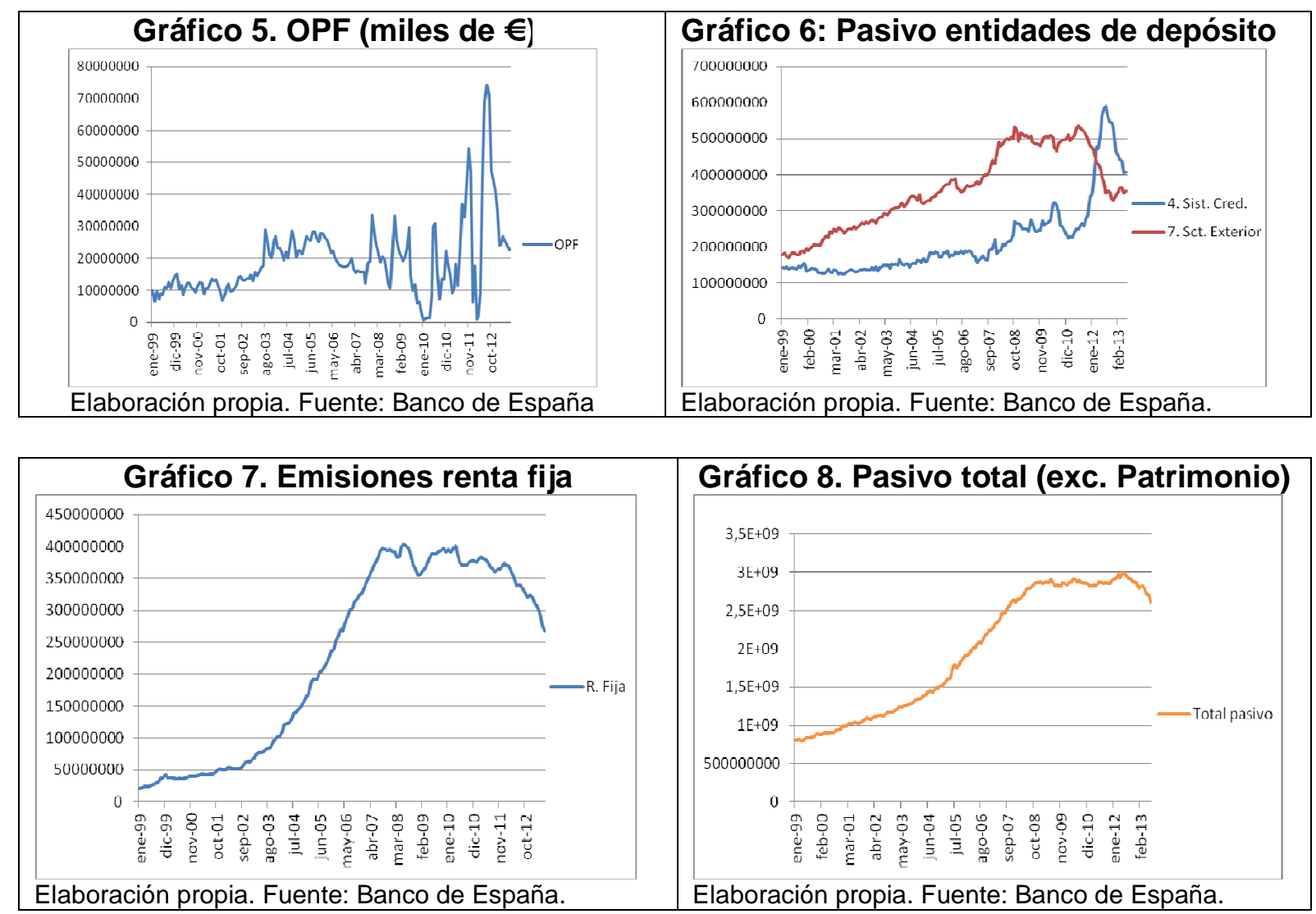

Es decir, el medio más regular por el cual las entidades de depósito acuden al BCE para intentar satisfacer sus necesidades de liquidez inmediatas son las OPF. Tal y como se observa en el mismo, la cantidad de dinero otorgada mediante OPF a las entidades españolas se multiplico por tres entre 1999 y 2005. Después desciende

\footnotetext{
${ }^{7}$ Pasivo total de las entidades de depósito según el boletín estadístico del Banco de España consta de: depósitos (residentes en España (entidades crédito, AA.PP. y OSR) y resto del mundo), valores distintos de acciones y participaciones (emisiones de renta fija), patrimonio (junto con ajustes y correcciones de valor), pasivos de obra benéfico-social, y periodificación y otros pasivos.
} 
Alonso, Fernando y Blázquez, Pablo. Carry trade y credit crunch en la economía española.

hasta mediados de 2007 y partir del estallido de la crisis, las fluctuaciones se hacen frecuentes y pronunciadas hasta la actualidad. El nuevo entorno de tipos de interés bajos, insólito en España, permitió un fuerte incremento del endeudamiento externo (sect. Externo), mientras que el endeudamiento entre entidades se mantuvo prácticamente constante. El gráfico 6 nos muestra esa tendencia y además el cambio de la misma como consecuencia de la incertidumbre y descenso de la credibilidad del sector financiero español a nivel internacional a raíz de la crisis. El gráfico 7 muestra la evolución de la emisión de valores de renta fija de las entidades españolas. El incremento entre 1999 y 2007 parece elevado. La confianza de emitir en euros y no en pesetas es uno de los factores explicativos de este cambio en la capacidad de emisión, pero también la innovación financiera que caracterizó este periodo puede haberla impulsado y por tanto reducido la capacidad de la política monetaria para controlarlo, tal y como expone el BCE:

The first decade of the monetary union coincided with an intense process of financial innovation. The fact that banks could easily securitize part of their loan portfolios and have proven increasingly capable of obtaining financing directly from financial markets has rendered the bank lending channel of monetary policy less effective in normal times ${ }^{8}$.

Todo lo comentado hasta ahora ayuda a explicar lo que nos muestra el gráfico 8 . Es considerable el aumento del pasivo de las entidades de depósito españolas durante el periodo 1999-2007. Este efecto, acontecido e incentivado por la política monetaria impulsó en la economía española un aumento de los créditos concedidos cuyo resultado fue una burbuja inmobiliaria de semejante importancia que llegó a convertirse en el pilar fundamental del crecimiento económico logrado durante dicho periodo, tal y como veremos en el siguiente apartado. Un modelo de crecimiento que viene a explicar en parte la profundidad de la crisis en la economía española.

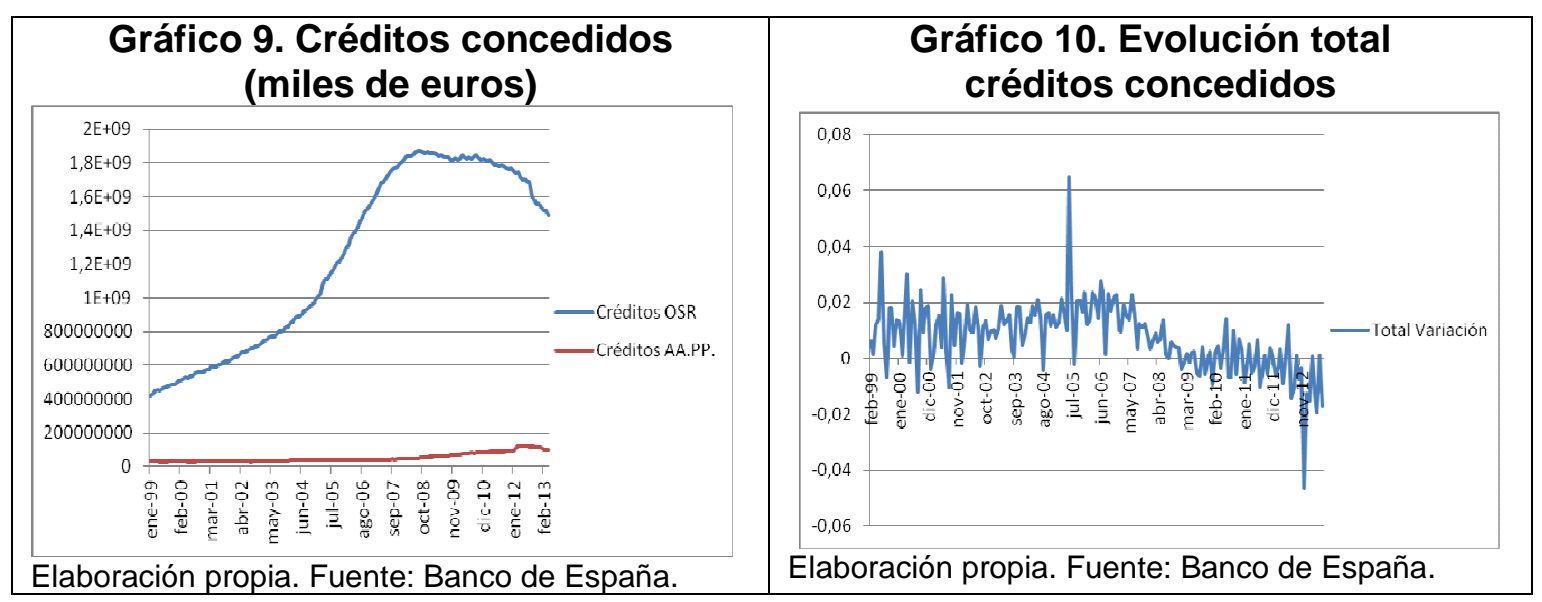

\section{DESTINO DEL CRÉDITO EN LA ECONOMÍA ESPAÑOLA ENTRE 1999 Y 2007}

El análisis de los sectores de la economía a los que se asignan los créditos nos ayuda a explicar el peso de los diferentes sectores dentro de la estructura económica de un país. La comprensión de la distribución del crédito es, por tanto, clave ya que nos muestra hacia donde se han focalizado las decisiones de inversión y consumo de los agentes económicos durante un periodo de tiempo determinado.

\footnotetext{
${ }^{8}$ ECB monthly boletin May 2010 p. 85

Papeles de Europa

Vol. 26, Núm. 2 (2013): 64-92
} 
Alonso, Fernando y Blázquez, Pablo. Carry trade y credit crunch en la economía española.

Haciendo dicho análisis no sólo sorprende la dimensión del crédito, sino su concentración sectorial.

Los gráficos 11 y 12 muestran la evolución del crédito otorgado entre el sector público y el sector privado, y dentro de este último, el destinado bien a empresas o bien a hogares entre 1999 y 2007. La diferencia entre el sector público y sector privado es muy amplia. Podríamos llegar a decir que la participación de las Administraciones públicas es prácticamente marginal y constantemente reducida a lo largo del periodo ${ }^{9}$. Dentro del sector privado, tanto los créditos otorgados a hogares como a actividades económicas han aumentado de forma muy pareja durante todo el periodo hasta el tercer trimestre de 2006 cuando las pendientes tienden a divergir. El gráfico 12, nos muestra el comienzo de la decadencia de la demanda de crédito por parte de los hogares, fenómeno determinante para la ralentización y reducción del consumo en que posteriormente se ahondaría durante la crisis. En cambio, el crecimiento del crédito otorgado a las empresas no desacelera. Estos dos gráficos nos ayudan en una comprensión superficial de la importancia de la actividad privada, tanto de empresas como de hogares en el desenvolvimiento económico del periodo. Ahora, veamos que hicieron las empresas y los hogares con esos créditos.
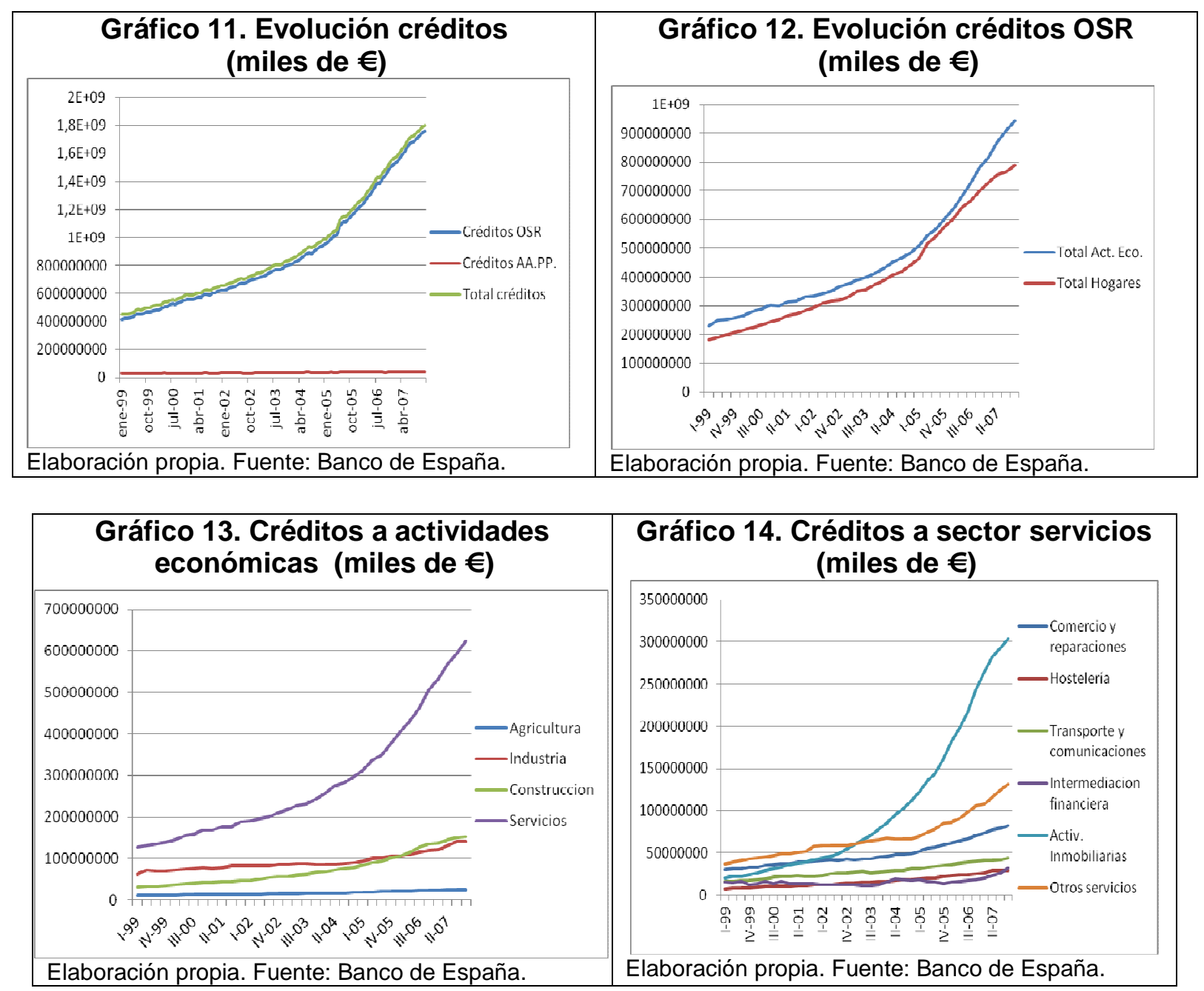

\footnotetext{
${ }^{9}$ Entre los años 1995 y 2007 la deuda pública sobre el PIB cayó del 70 al 34\%, además se duplicó el porcentaje de deuda española en manos extranjeras. Ello explicaría en parte la caída del crédito concedido a las Administraciones Públicas.
} 
Alonso, Fernando y Blázquez, Pablo. Carry trade y credit crunch en la economía española.

En los dos gráficos expuestos arriba, observamos el predominio de los créditos otorgados al sector construcción y dentro del sector servicios a los relacionados con las actividades inmobiliarias. Es ilustrativo ver que en apenas cinco años, entre 2002 y 2007, la composición de la estructura de créditos cambie de forma tan profunda. Pero el cambio cualitativo no solo es significativo sino también el ritmo de aumento constate y elevado de la cantidad de créditos en términos cuantitativos. La trayectoria fue una tendencia creciente, retroalimentada por sí misma, y facilitada por la política monetaria común, que modificó la estructura productiva española y creó una burbuja inmobiliaria de gran magnitud cuyo colapso ha tenido tal repercusión que sigue vigente con un stock de más de 1 millón de viviendas sin vender, cuyos precios han caído un $50 \% 6$ años después del comienzo de la crisis. Uno de los hechos más representativos de la burbuja inmobiliaria es que para el año 2007, el volumen de créditos otorgados al sector construcción superó al del conjunto de la industria.

A continuación se muestra el gráfico 15 correspondiente al destino del crédito de los hogares. En él vemos que el principal destino del crédito fue la adquisición de vivienda. Además vemos que cuantitativamente el crecimiento del crédito otorgado fue muy notable. En definitiva, el análisis de la distribución del crédito otorgado nos da una impresión de la magnitud del crecimiento del endeudamiento y de la focalización del mismo en torno a una misma actividad económica. Tanto productores como consumidores estuvieron de forma constante y creciente endeudándose, dando lugar una burbuja inmobiliaria y de crédito de gran magnitud, llegando a representar los créditos destinados a la burbuja (actividad económica construcción, servicios inmobiliarios, gasto hogares adquisición y rehabilitación de viviendas) el $60 \%$ del total de créditos otorgados en la economía para diciembre de 2007.

\section{Gráfico 15. Destino del crédito de los hogares (miles de $€$ )}

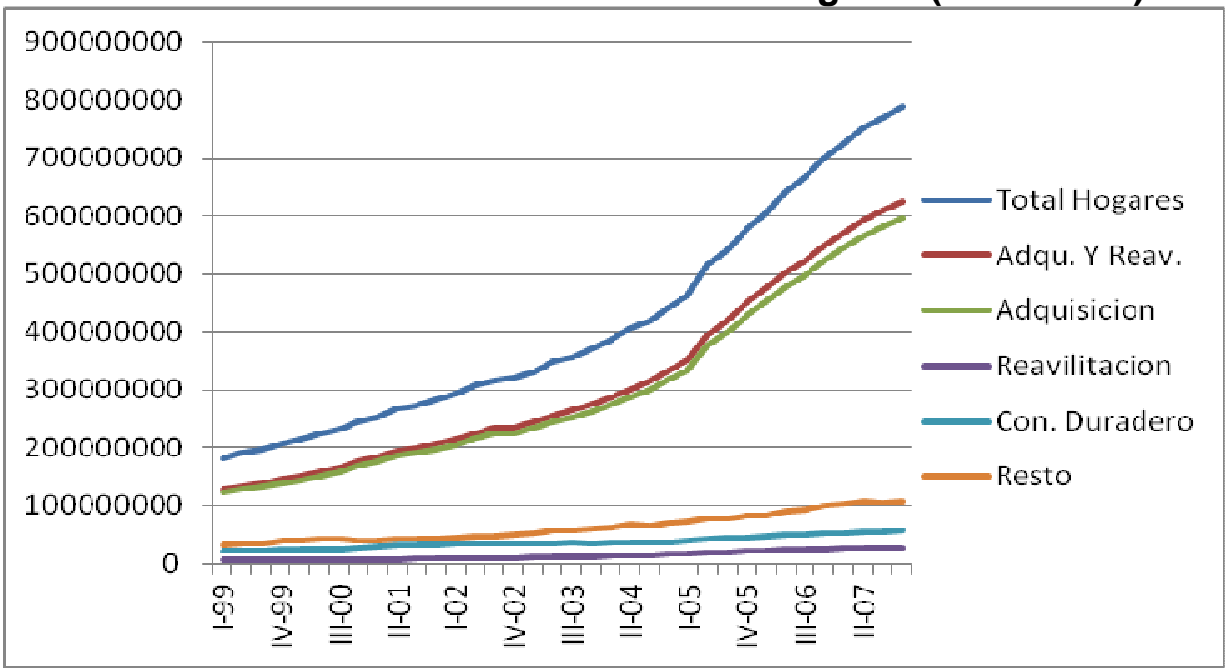

Elaboración propia. Fuente: Banco de España

En consonancia con lo planteado podemos concluir que el periodo que va desde 1999 hasta 2007 ha sido de profundos cambios en la cantidad y destino del crédito. Siendo el protagonista absoluto el sector privado frente al sector público. Tanto empresas con 900 mil millones como los hogares con 800 mil millones han incrementado su endeudamiento de forma elevada, es decir, tanto productores como consumidores fueron, mediante endeudamiento intenso, instigadores de la 
Alonso, Fernando y Blázquez, Pablo. Carry trade y credit crunch en la economía española.

concentración del crédito. Este proceso puede parecer a día de hoy tanto sorprendente como insostenible pero ni las entidades de crédito ni las instituciones trataron de persuadirlo. Cercano el colapso, en el año 2007 pocas eran las voces críticas y el respaldo institucional a la situación era manifiesto.

\section{REESTRUCTURACIÓN DEL CRÉDITO 2008-2013}

\subsection{Proceso de reestructuración y carry trade}

Tras el auge de la concesión de crédito visto entre 1999 y 2007, se ha gestado una contracción que desde 2008 no parece haber tocado fondo a día de hoy. Sin embargo, a pesar de que se ha producido en términos absolutos, existen diferencias entre sectores, siendo las administraciones públicas mejor tratadas que el sector privado en su conjunto. La profundidad de la crisis económica podría explicar por sí misma la contracción crediticia en el sector privado, la crisis financiera e inmobiliaria parecen suficientes motivos para ello, a pesar de las medidas excepcionales de inyección de liquidez implementadas por el Banco Central Europeo. Veamos la evolución:

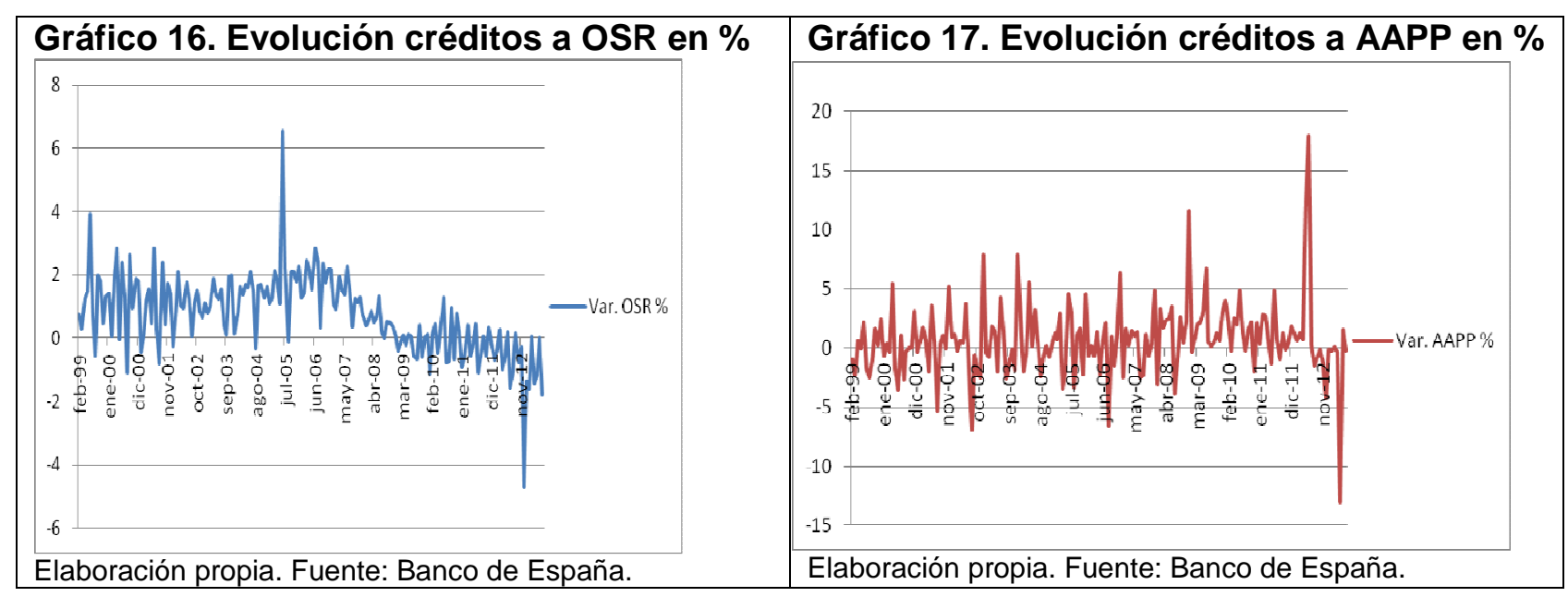

Los gráficos 16 y 17 nos muestran las variaciones de los créditos concedidos a Otros Sectores Residentes y a las Administraciones Públicas. La contracción en los créditos en el sector privado es muy significativa. La pendiente negativa significa que el monto total de euros en crédito se reduce, es decir, que los créditos liquidados son superiores a los emitidos de forma que la cantidad en euros total en crédito vivo disminuye. Las tasas de variación constantemente positivas del periodo anterior a 2007 desaparecen. La tendencia es contraria en el sector público, manteniéndose cercana a cero hasta 2007, y visiblemente positiva hasta 2011 en consonancia con la implementación de políticas fiscales expansivas. Empero, el cambio de política económica hacia posiciones más austeras parece que hace cambiar la tendencia de nuevo. Las políticas de austeridad marcadas por Europa han limitado las necesidades de financiación de las Administraciones Públicas. Veamos ahora cómo ha evolucionado la concesión de créditos dentro del sector privado. 


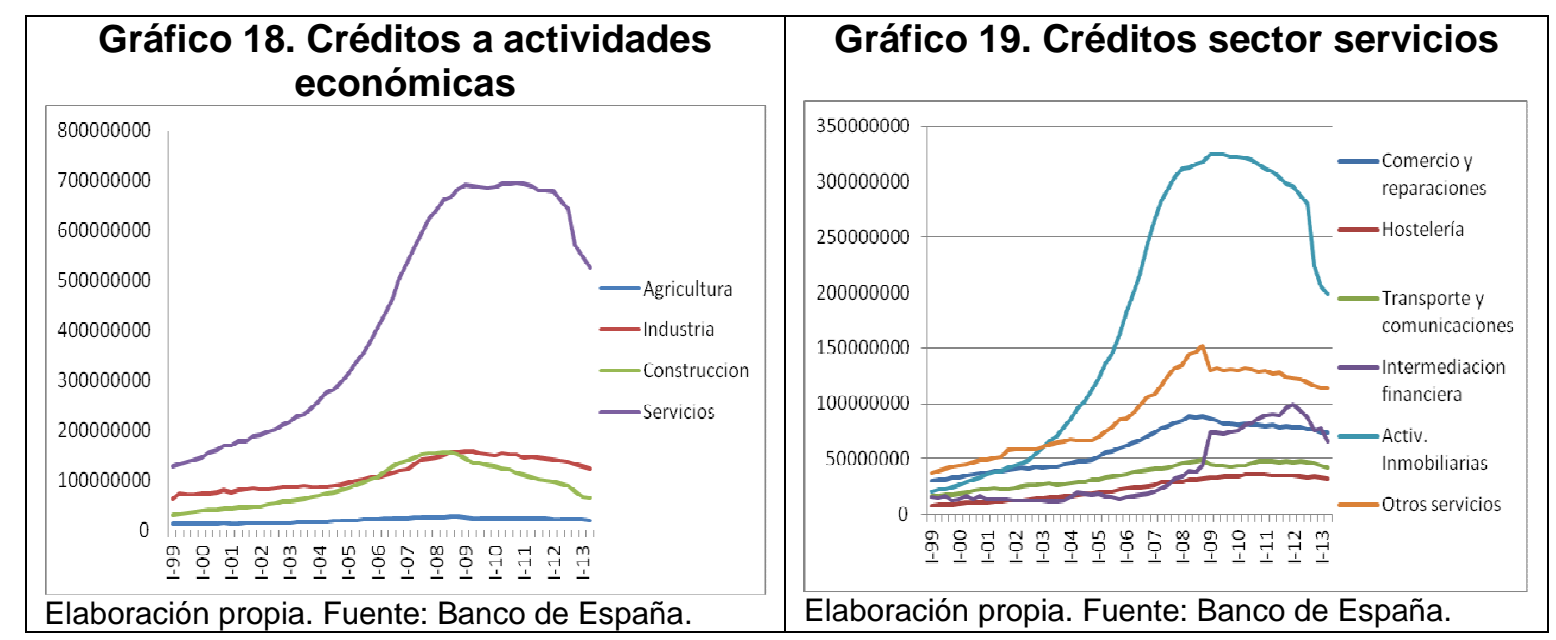

Gráfico 20. Evolución del crédito a los hogares

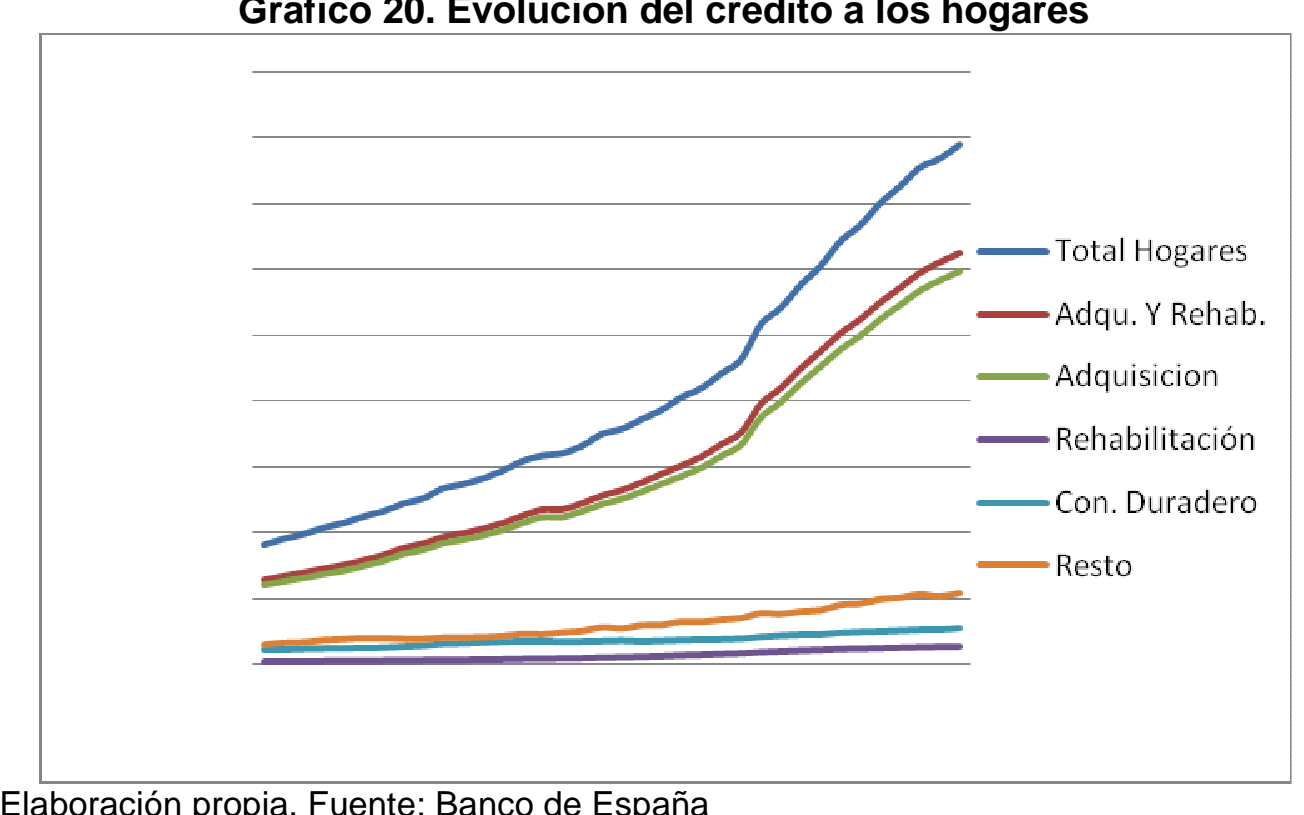

Elaboración propia. Fuente: Banco de España

Los gráficos 18 y 19 (ambos expresan cantidades en miles de €) muestran la evolución de los créditos concedidos a las empresas por sectores. La conclusión es evidente: la caída de los créditos se concentra en el sector que en la etapa anterior había sido favorecido. En la actualidad, la cantidad de dinero en créditos en el sector construcción se ha reducido en más de la mitad de la cantidad desde 2007 y, dentro del sector servicios, los relacionados con actividades inmobiliarias se han reducido en un tercio. La industria, aunque también está siendo perjudicada, parece mantenerse a pesar de que la tendencia sea levemente negativa. En los hogares el volumen de endeudamiento es similar en términos globales al alcanzado en 2007. Éste estancamiento se explica por la no concesión de nuevos créditos desde entonces y porque los créditos hipotecarios, que son los protagonistas, tienen una prolongada duración y por tanto los efectos de su liquidación se demorarán en el tiempo. En definitiva, el análisis expuesto explica el proceso de contracción del crédito a todos los niveles dentro del sector privado y el ligero aumento aunque con perspectiva de corrección en el sector público. Una contracción especialmente concentrada en el sector construcción y de servicios inmobiliarios, los cuales fueron profundamente beneficiados durante el periodo 1999-2007. 
Desde el año 2008 el Banco Central Europeo ha intentado luchar contra la crisis financiera a través de diferentes vías. Este frente de actuación ha tenido como objetivo restablecer y facilitar el acceso a financiación del sistema financiero en su conjunto con el objeto de conseguir la refinanciación y la liquidez necesaria para el correcto funcionamiento del sistema. Las vías de actuación se han sucedido tras los años y se pueden exponer de forma resumida de la siguiente manera: en agosto de 2007 ofrece liquidez extra tanto en euros como en dólares; en octubre de 2008 empieza a ejecutar un nuevo mecanismo de acceso a liquidez a una semana con un tipo fijo, otorgando tanta liquidez como la entidad pueda garantizar con colateral; en junio de 2009 lleva a cabo un programa de compra de bonos; En 2010, estableció el programa Secuirities market, con el cual intervino en los mercados secundarios de bonos, especialmente en el de deuda pública junto con los bancos nacionales de los países para calmar las tensiones en los países periféricos. En diciembre de 2011 ejecuta la mayor operación de inyección de liquidez mediante dos programas de compra ilimitada con vencimiento a 36 meses, uno para diciembre de 2011 y otro en febrero de 2012. Ante la implementación de estas medidas extraordinarias, las entidades de depósito españolas han aumentado progresivamente su exposición al BCE.

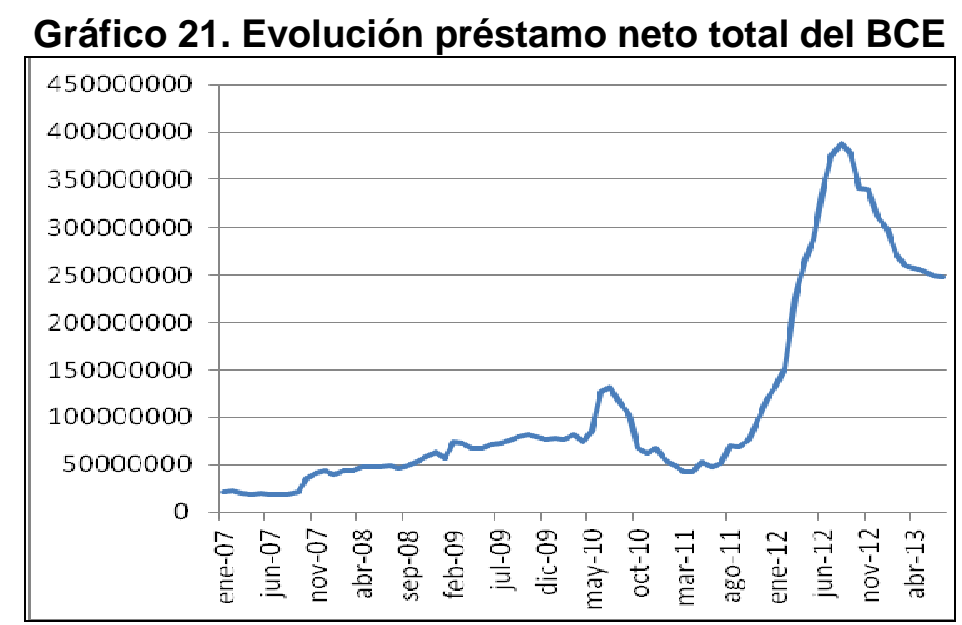

Elaboración propia. Fuente: Banco de España

Tal y como muestra el gráfico 21, la exposición de las entidades de depósito españolas al BCE ha aumentado de forma constante y especialmente a partir de finales de 2011. El objetivo del BCE de garantizar la solvencia y liquidez del sistema financiero es para que éste cumpla su función esencial como prestamista de crédito, tanto para la mejora de actividad económica en general como para el correcto funcionamiento del mecanismo de transmisión de la política económica, de forma que el BCE siga contando con su canal de actuación de forma eficaz. Anteriormente hemos demostrado que la cantidad de créditos concedidos por las entidades de crédito españolas no han parado de descender desde 2008 en todo el sector privado y aumentado de forma leve en el sector público. En cambio, la deuda pública no ha parado de crecer desde el inicio de la crisis y la desconfianza internacional en contra de la deuda pública española ha sido manifiesta. Estos factores nos llevan irremediablemente a plantear la hipótesis de que han sido las entidades de crédito españolas las que a través de sus líneas de financiación baratas con el BCE han comprado parte de esas nuevas emisiones de deuda pública, incurriendo en un claro carry trade. 
Alonso, Fernando y Blázquez, Pablo. Carry trade y credit crunch en la economía española.

El gráfico 22 expone, en miles de $€$, las cantidades de valores distintos de acciones y participaciones situadas en el activo de las entidades de crédito. El gráfico 23 muestra, en miles de $€$, las emisiones de deuda neta de los sectores económicos administraciones públicas, instituciones financieras e instituciones no financieras. Dejamos a un lado las emisiones netas de las entidades no financieras al ser cercanas a cero y sin oscilaciones. Con estos dos gráficos y la explicación de las medidas excepcionales implementadas por el BCE se pueden establecer interrelaciones. Entre 2007 y 2008 el incremento de los valores situados en los activos es relativamente pequeño. Durante ese periodo, las emisiones de deuda neta de las instituciones financieras son muy oscilantes y las de deuda pública empiezan a mantenerse en cantidades positivas y cercanas a los 150 mil millones, una cantidad ciertamente elevada con respecto al periodo anterior. El primer incremento sustancial de valores en manos de las entidades de crédito se produjo a partir de 2009 cuando la exposición de la banca al BCE se había multiplicado por tres desde 2007 y coincidiendo con el incremento de las emisiones de deuda pública y la reducción de la de las instituciones financieras. Entre mediados de 2009 y 2011 el incremento de los valores en los activos se mantiene en consonancia con el programa de compra de bonos del BCE, periodo durante el cual la exposición de las entidades al BCE disminuye. Es a partir de la primera de las dos inyecciones ilimitadas de liquidez a finales de 2011 cuando tanto la exposición de la banca al BCE y la compra de valores por parte de las entidades de crédito aumenta de forma elevada, al tiempo que las emisiones netas de deuda pública aumentan y se mantienen constantes mientras que la de las instituciones financieras se reducen a niveles negativos. En suma, la evidencia empírica nos expone una tendencia a favor del la hipótesis del carry trade en España, es decir, acceso a un interés reducido por parte del BCE y la compra de deuda pública, con riesgo ínfimo, con intereses superiores (hipótesis 1).

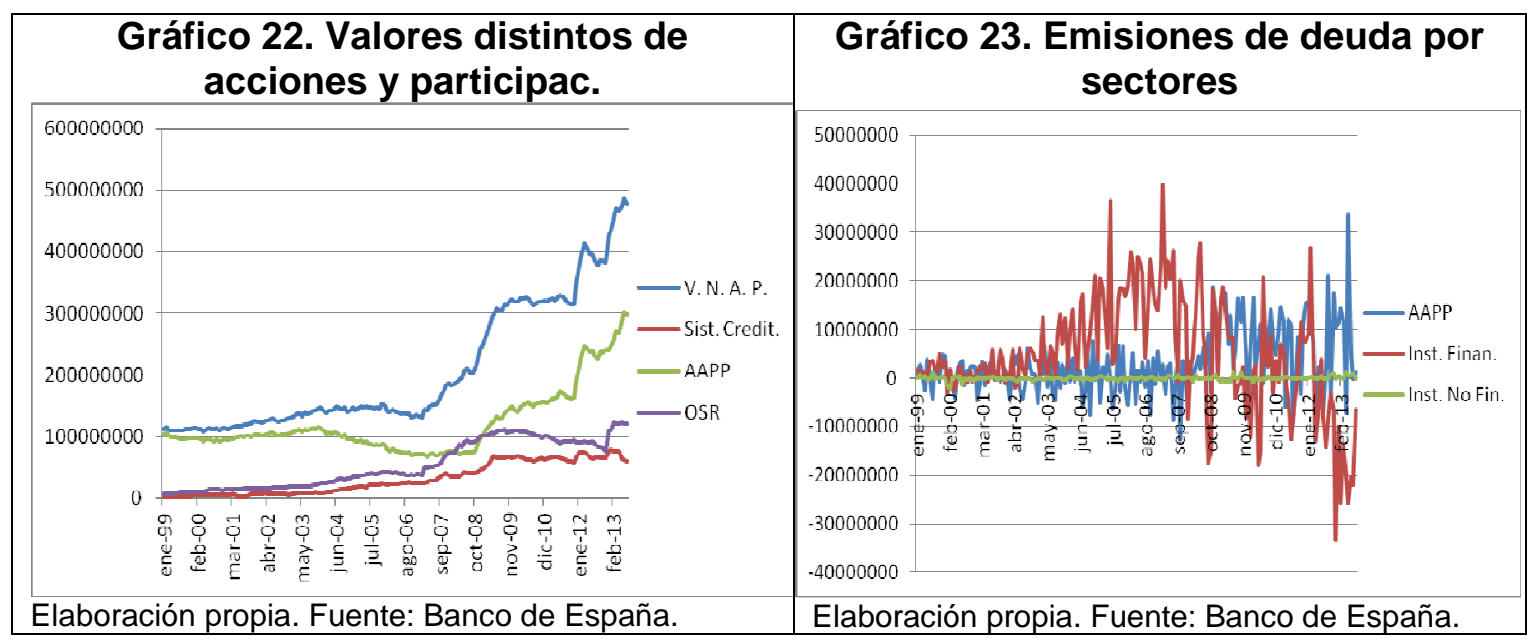

\subsection{El problema de la morosidad}

Tal y como hemos visto anteriormente, desde 1999 se ha desarrollado un proceso de concentración del crédito en torno al sector construcción y servicios inmobiliarios que desarrolló una burbuja inmobiliaria que acabaría explotando a finales de 2007. Como consecuencia, se sucedieron las quiebras y los impagos, muchos de ellos vinculados al sector construcción, que acabaron lastrando los balances de las mismas entidades de crédito que habían incentivado la concentración. Ha sido este 
Alonso, Fernando y Blázquez, Pablo. Carry trade y credit crunch en la economía española.

problema, junto con una crisis que ha ido mucho más allá de lo financiero y lo inmobiliario, la principal causa de la contracción del crédito en el sector privado y la consiguiente apuesta por la deuda pública teóricamente libre de riesgo. Veamos la evolución de las tasas de morosidad y de dudoso cobro.

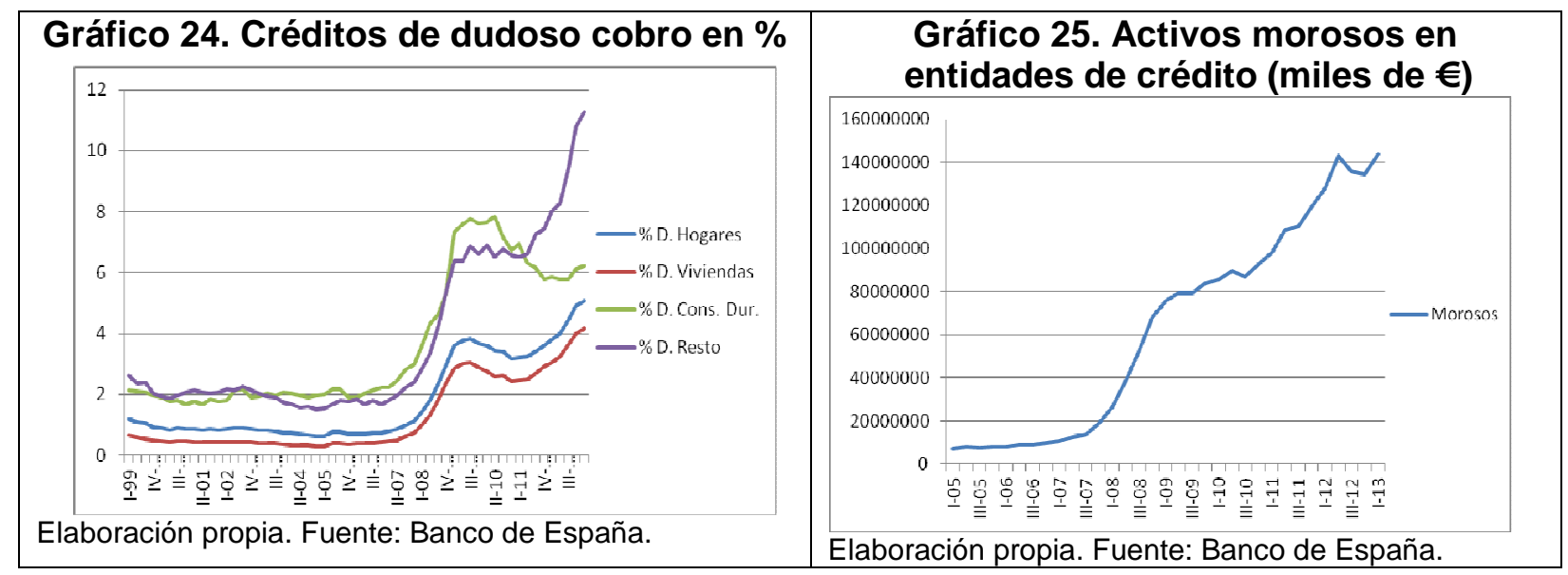

En primer lugar ha de mencionarse que los datos de morosidad no se encuentran desagregados por sectores al contrario que con los de dudoso cobro, bien es comprensible de asociar que en el sector que más créditos de dudoso cobro existen serían los que más acaban convirtiéndose en morosos. El gráfico 24 expone en porcentaje los créditos de dudoso cobro en manos de las entidades de crédito por sectores. Ha de destacarse que a pesar de fueron mayor cantidad de euros en créditos otorgados a los hogares que a actividades productivas el tanto por ciento de créditos dudosos de las segundas es el triple de los primeros. Dentro de las actividades productivas destaca de forma agresiva el sector construcción frente a todos los demás, aunque todos han aumentado notablemente desde el inicio de la crisis. Con respecto a los hogares, destaca que los créditos dudosos relacionados con adquisición y rehabilitación de viviendas son los menores en cuanto a porcentaje justamente en la misma sección en las que se concentraron más los créditos. La razón resulta obvia y es que los hogares están haciendo todo lo posible y renunciando a todo lo demás por mantener sus viviendas. El gráfico 25 nos muestra la cantidad de euros de activos morosos, la cual no ha parado de aumentar considerablemente desde 2007. En suma, resulta importante enfatizar la concentración de créditos dudosos en las actividades productivas y el bajo porcentaje de los hogares (hipótesis 2).

\section{CONCLUSIONES}

La crisis de crédito de la economía española se debe fundamentalmente a los factores desarrollados y contrastados con los datos de las hipótesis formuladas en el artículo. Una asignación dirigida del crédito hacia el sector construcción y de servicios inmobiliarios generó una estructura crediticia anómala con un riesgo de crédito muy concentrado sectorialmente. La crisis dejó al descubierto esas debilidades. El supervisor, ante la imposibilidad de intervenir de forma directa para cubrir los desfases, desequilibrios y descubiertos, inherente a su propio diseño, se vio obligado a intervenir de forma encubierta mediante inyecciones de liquidez al sistema que han proporcionado beneficios extraordinarios a las entidades de crédito con los que cubrir sus desfases patrimoniales y morosidades crediticias. Estas 
Alonso, Fernando y Blázquez, Pablo. Carry trade y credit crunch en la economía española.

posibilidades pusieron en marcha estrategias de carry trade que absorbieron cantidades ingentes de recursos que, según el mecanismo de transmisión de la política monetaria, debieran haber concluido en la concesión de créditos a empresas y familias.

Las reformas impulsadas durante la crisis para endurecer las exigencias de capital "de alta calidad" a las entidades de crédito han actuado en un doble sentido restringiendo el crédito: por una parte las entidades necesitan guardar recursos para la constitución de fondos de libre disposición que computen en los ratios en los que cada vez se endurecen más las condiciones para que sean considerados activos líquidos y sin riesgo, lo que exige una mayor inmovilización de recursos; por otra, el riesgo de impago y el aumento de la morosidad obligan a dotar provisiones para insolvencias y a destinar mayores recursos para la cobertura de los créditos al consumo.

Por si ello fuera poco, las Administraciones Públicas alcanzarán una deuda pública sobre el PIB del mismo tamaño que el Producto Interior Bruto. Esto está requiriendo que las entidades de crédito participen de forma activa en los mercados de deuda, asignando el dinero a una rentabilidad con la que no pueden competir los demandantes de recursos privados.

Para solventar esta situación y que el crédito fluya, el BCE debe regular el uso del carry trade limitándolo. El sector público debe liberar parte de su demanda de crédito para evitar el crowding out sobre el sector privado, y esto sólo resultará mediante un control de las finanzas públicas y una gestión más eficiente de lo público. Los nuevos requerimientos de solvencia de Basilea III deben armonizarse en relación al momento del ciclo económico: es necesario que las entidades cubran con capital de calidad los ratios, pero resultará mucho más sencillo hacerlo con menores tasas de morosidad y menores provisiones para insolvencias. La suma de todas estas propuestas llevaría a una mejor gestión del riesgo de crédito y a lograr que su destino sean las actividades productivas generadoras de empleo. 
Alonso, Fernando y Blázquez, Pablo. Carry trade y credit crunch en la economía española.

\section{REFERENCIAS}

AGUADO, P. G. F., UREÑA, A. P. \& PONCE, A. T. (2013): Sistemas de Garantía de Depósitos: Impacto de la propuesta de la UE en el sector bancario español. Universia Business Review, 86-103.

ALBENTOSA, M. A. P. \& PACHECO, G. M. S. (2009): Un estudio empírico de transmisión monetaria en Europa. Información Comercial Española, ICE: Revista de economía, 163-192.

ALONSO GUINEA, F. \& CENDEJAS BUENO, J. L. (2012): Integracion monetaria y financiera en el periodo de crisis: los diferenciales de deuda como instrumentos de medida.

ANAND, G., KUTSAROV, I., MAIER, T. \& STORR, M. (2013): The Influence of Macroeconomic and Behavioral Factors on Tactical Strategy Allocation (TSA) for Funds of Hedge Funds. The Journal of Wealth Management, 16, 63-76.

ANDRÉS, G. G. (2003): La política macroeconómica del euro: un balance crítico. Boletín económico de ICE, Información Comercial Española, 7-28.

BARCLAYS (2013): ECB: No rush on policy rates. Euromoney markets.

BDE, B. D. E. (2000-2013): Boletín Económico.

BDE, B. D. E. (2010-2013): Informe de estabilidad financiera.

BERNARDINO, A. C. \& ALCÁZAR, M. D. M. P. 2007. Los efectos diferenciales de la política monetaria del BCE a través de los mecanismos de transmisión de la Eurozona. Boletín económico de ICE, Información Comercial Española, 25-38.

BRONER, F., ERCE, , A., MARTIN, A. \& VENTURA, J. 2013. Sovereign Debt Markets in Turbulent Times: Creditor Discrimination and Crowding\% Out Effects.

CABELLO, V. R. \& URRA, I. 2009. Impacto de la crisis en el modelo de gestión de activos. Bolsa: revista mensual de bolsas y mercados españoles, 28-37.

CANAL, P. Á. 2001. El coeficiente de solvencia de las entidades de crédito españolas. Estabilidad financiera, 171-192.

CAO, C., CHEN, Y., LIANG, B. \& LO, A. W. 2013. Can Hedge Funds Time Market Liquidity? Journal of Financial Economics.

CATARINEU, E. \& PÉREZ, D. 2008. La titulización de activos por parte de las entidades de crédito: el modelo español en el contexto internacional y su tratamiento desde el punto de vista de la regulación prudencial. Estabilidad financiera, 14, 88-121.

CLIMENT SERRANO, S. 2013. La reestructuración del sistema bancario español tras la crisis y la solvencia de las entidades financieras. Consecuencias para las cajas de ahorros. Revista de Contabilidad.

COMUNIDADES EUROPEAS, C. 1989. Directiva 89/647/CEE sobre coeficiente de solvencia de las entidades de crédito. Diario Oficial de las Comunidades Europeas, 14-22.

CHOSSUDOVSKY, M. \& MARSHALL, A. G. 2010. The global economic crisis, GLOBAL RESEARCH, CENTRE FOR RESEARCH ON.

DE GRAUWE, P. 2012. Economics of monetary union, Oxford University Press.

DE GRAUWE, P. \& VANHAVERBEKE, W. 1993. Is Europe an optimum currency area? Evidence from regional data. Policy issues in the operation of currency unions, 111-29.

DE MIGUEL-DOMÍNGUEZ, J. C., MIRANDA-TORRADO, F., PALLAS-GONZÁLEZ, J. \& PERAZA-FANDIÑO, C. 2003. La medición del riesgo de crédito y el nuevo acuerdo de capital del Comité de Basilea. Universidad de Santiago de Compostela. Facultad de Ciencias Económicas y Empresariales.

DíAZ, A. F. 2011. Política monetaria. Fundamentos y estrategias, Editorial Paraninfo.

DUNNE, P. G., FLEMING, M. J., ZHOLOS, A. \& CAPITAL, B. A Microstructure Perspective on Liquidity Interventions and the Interbank Repo Market During the Recent Financial Crisis.

ECB, E. C. B. 2010-2013. monthly bulletin.

$E C B, E$. C. B. 2012. Survey on the access to finance of SMEs in the euro area (SAFE)

ESTEVE GARCÍA, V. \& PRATS ALBENTOSA, M. A. 2007. El mecanismo de transmisión de la política monetaria en la economía española y en el conjunto de la UEM.

GUIDE, R. S. 2013. The European Union and the Economic Crisis. European Union Politics, 367.

GUILLÉN, H. 2009. La crisis financiera de los préstamos subprime. Comercio Exterior, 59, 947-969.

Papeles de Europa

Vol. 26, Núm. 2 (2013): 64-92

http://dx.doi.org/10.5209/rev_PADE.2013.v26.n2.44184 
Alonso, Fernando y Blázquez, Pablo. Carry trade y credit crunch en la economía española.

HEIN, E., TRUGER, A. \& VAN TREECK, T. 2012. The European financial and economic crisis: Alternative solutions from a (Post-) Keynesian perspective. The Euro Crisis, 8, 35.

KRISHNAMURTHY, A. \& NAGEL, S. ECB Policies involving Government Bond Purchases.

LAN, Y., WANG, N. \& YANG, J. 2013. The economics of hedge funds. Journal of Financial Economics.

MAUDOS, J. 1996. Eficiencia, cambio técnico y productividad en el sector bancario español: una aproximación de frontera estocástica. Investigaciones Económicas, 20, 339-358.

ONTIVEROS, E. 2000. Globalización financiera y soberanía económica. Moneda y crédito, 111-152.

REGATO, E. O. 2000. La política monetaria en la zona del euro. Información Comercial Española, ICE: Revista de economía, 37-44.

RICARDO, D., GONNER, E. C. K. \& LI, Q. 1819. The principles of political economy and taxation, World Scientific.

RODRÍGUEZ, C. P., IGLESIAS, J. M. G. \& GAMALLO, R. N. 2010. La gestión de la liquidez del Banco Central Europeo durante la crisis financiera: 2008-2009. EAWP: Documentos de trabajo en análisis económico= Economical Analysis Working Papers, 9, 1.

TRILLO DEL POZO, D. \& ALONSO, N. 2013. La respuesta de la regulación prudencial a la crisis: Basilea III.

VEGA, J. L. \& BDE, B. D. E. 1992. El papel del crédito en el mecanismo de transmisión monetaria, Banco de España.

VILARIÑO, Á. 2009. Formación de burbujas financieras y crisis: de la crisis del Nasdaq a la crisis de la hipotecas subprime. Papeles de Europa, 19, 4-28.

VILARIÑO SANZ, Á. 2001. Sistema financiero español, Ediciones Akal.

VILLARROYA, J. M. \& DE GUEVARA RADOSELOVICS, J. F. 2008. El sector bancario español en el contexto internacional: evolución reciente y retos futuros, Fundacion BBVA.

WEEKLY, E. M. M. 2013. ECB: No rush on policy rates. Europe. 
Alonso, Fernando y Blázquez, Pablo. Carry trade y credit crunch en la economía española.

\section{ANEXO}

AGREGADOS MONETARIOS Y CREDITICIOS
Tasas de variación interanual

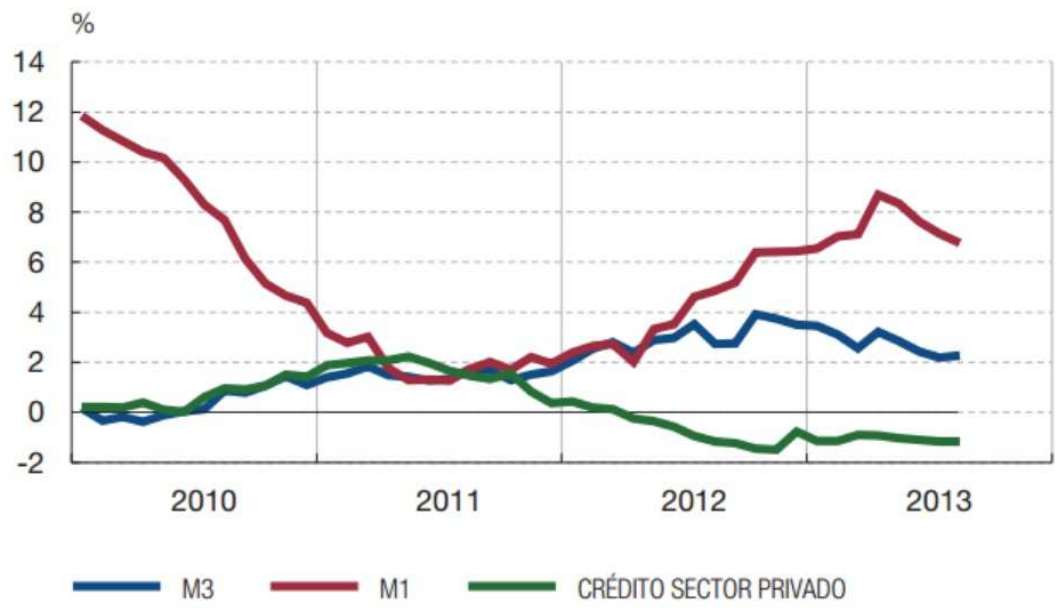

Fuente: BDE (VV.AA.): Boletín Económico; BDE (VV.AA.): Informe de estabilidad financiera.

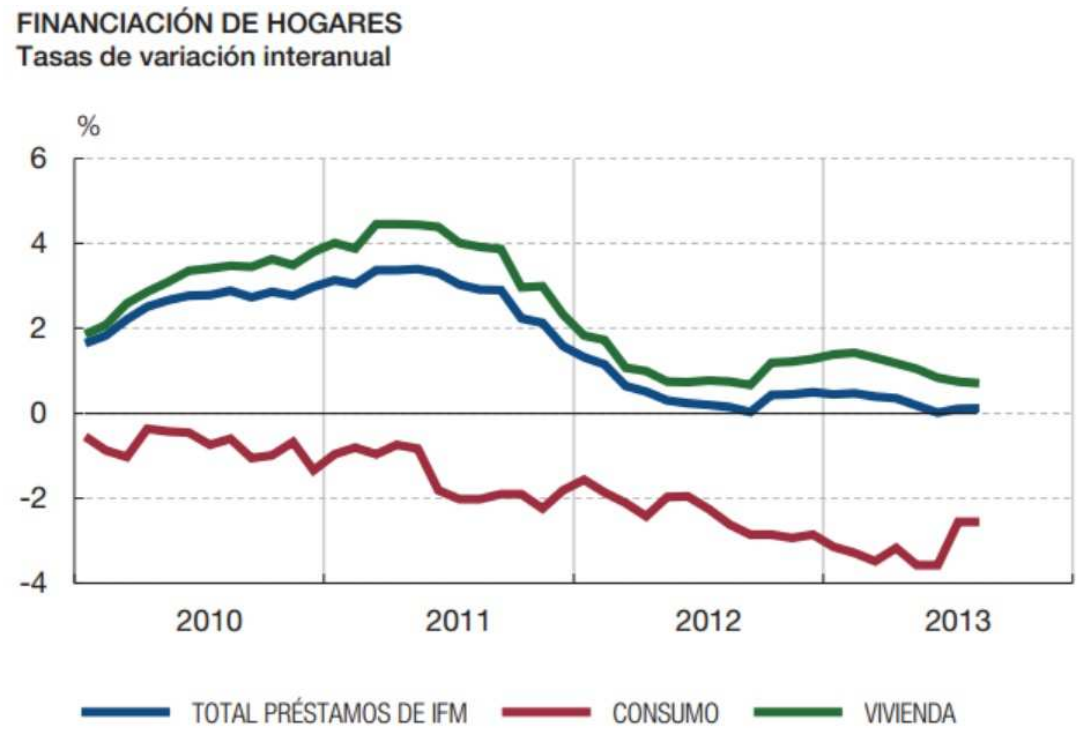

Fuente: BDE (VV.AA.): Boletín Económico; BDE (VV.AA.): Informe de estabilidad financiera. 
Alonso, Fernando y Blázquez, Pablo. Carry trade y credit crunch en la economía española.

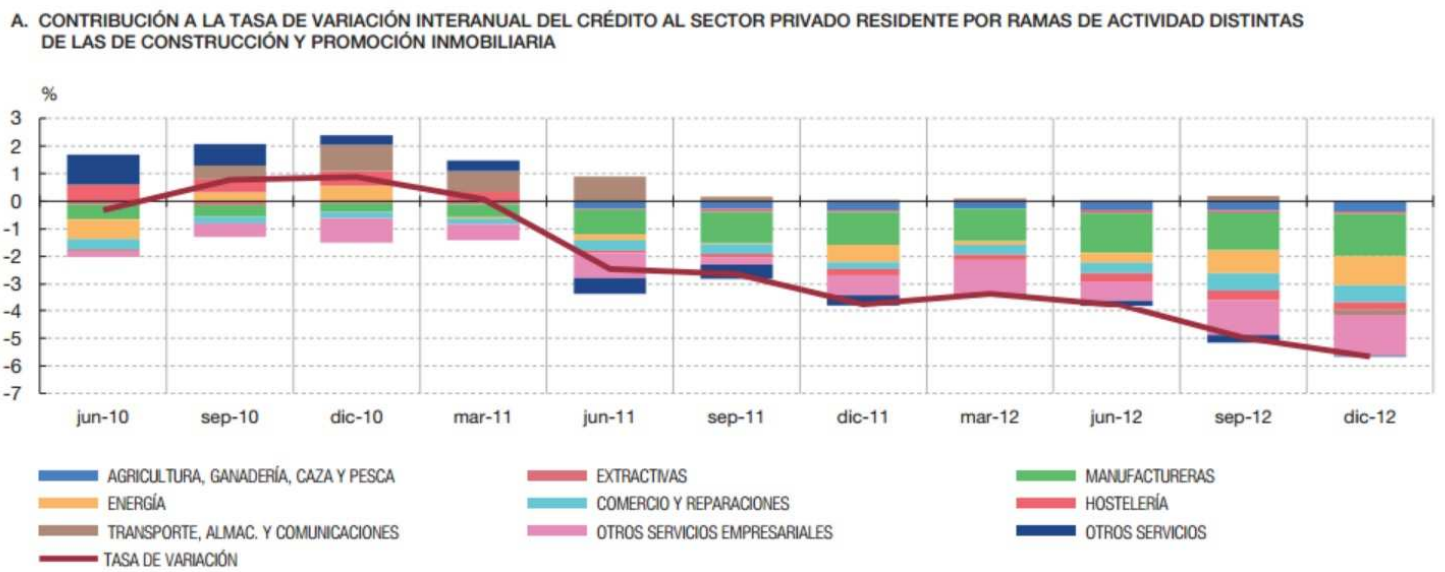

Fuente: BDE (VV.AA.): Boletín Económico; BDE (VV.AA.): Informe de estabilidad financiera.
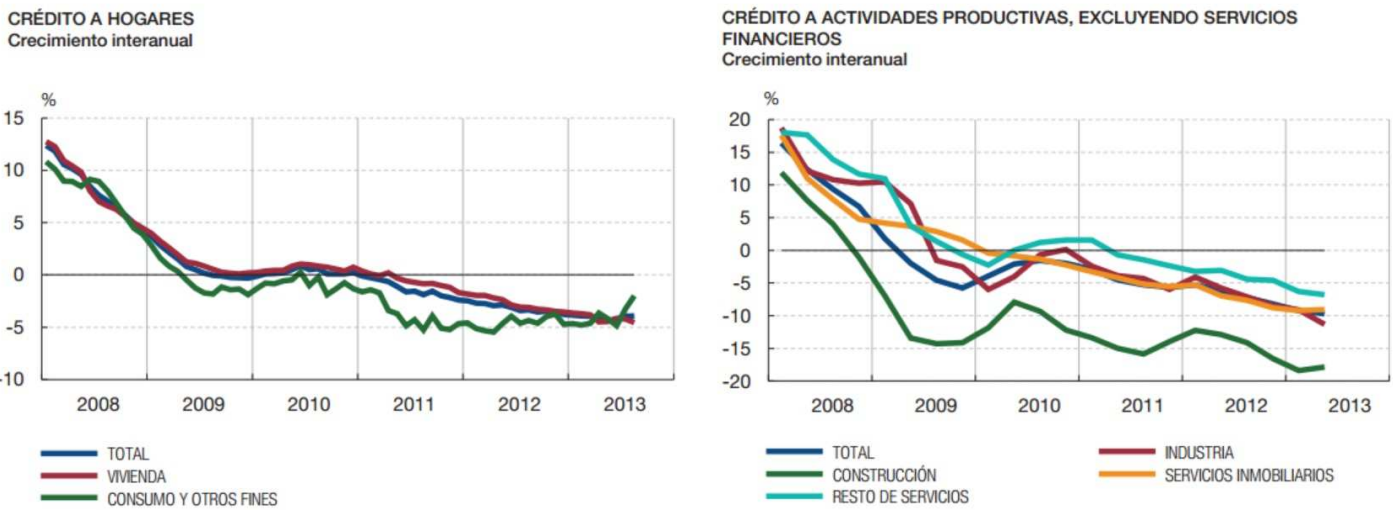

Fuente: BDE (VV.AA.): Boletín Económico; BDE (VV.AA.): Informe de estabilidad financiera.

RATIOS DE MOROSIDAD DEL CRÉDITO AL SECTOR PRIVADO RESIDENTE

GRÁFICO 2.6 Negocios en España, DI. Entidades de depósito

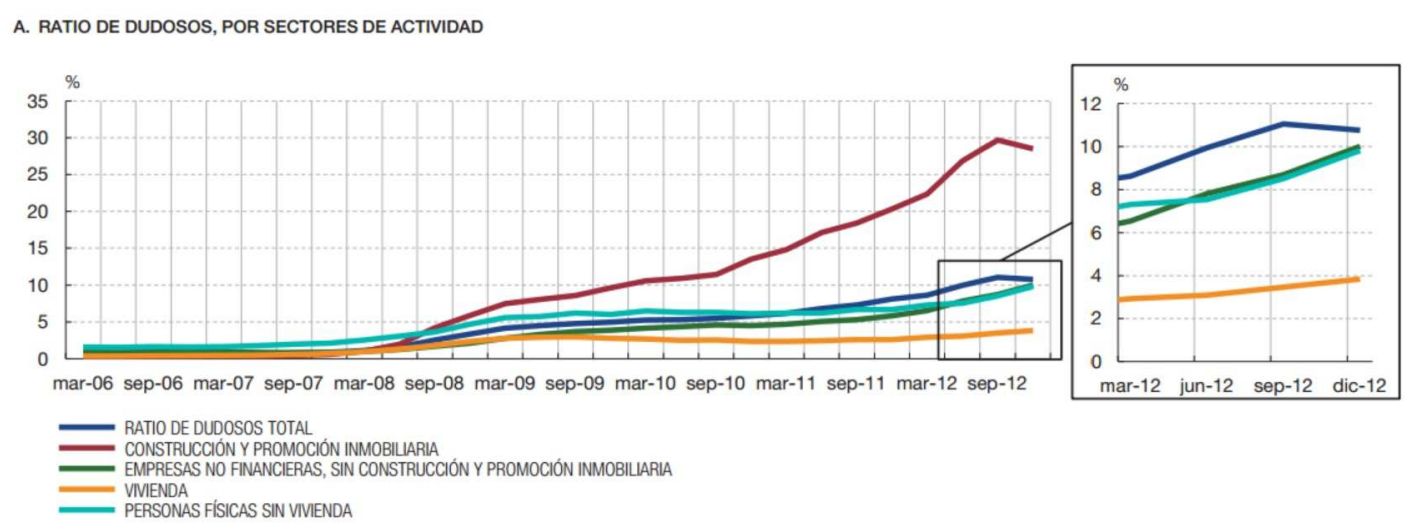

Fuente: BDE (VV.AA.): Boletín Económico; BDE (VV.AA.): Informe de estabilidad financiera. 
Alonso, Fernando y Blázquez, Pablo. Carry trade y credit crunch en la economía española.

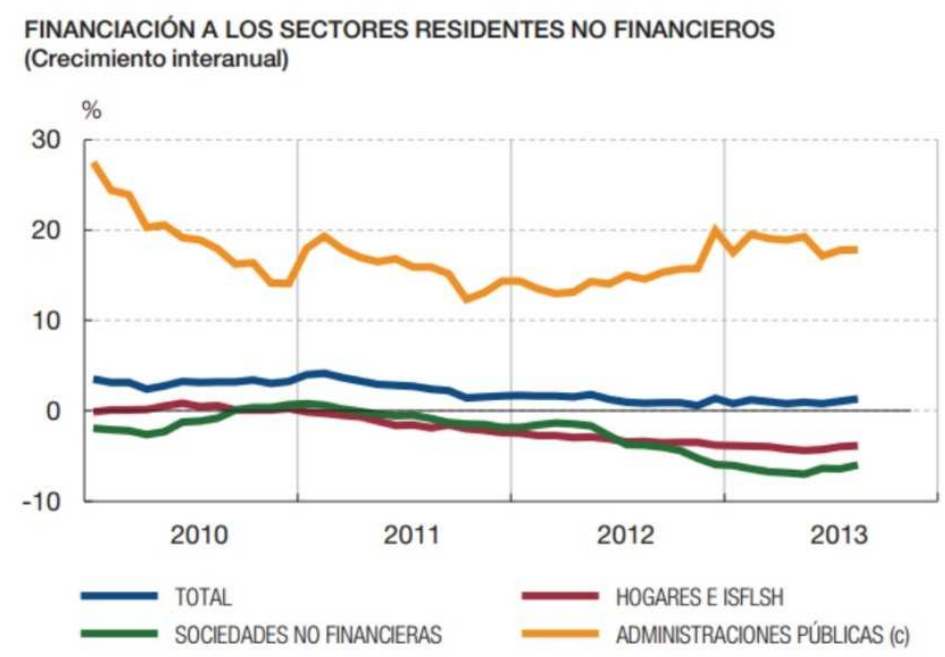

Fuente: BDE (VV.AA.): Boletín Económico; BDE (VV.AA.): Informe de estabilidad financiera.
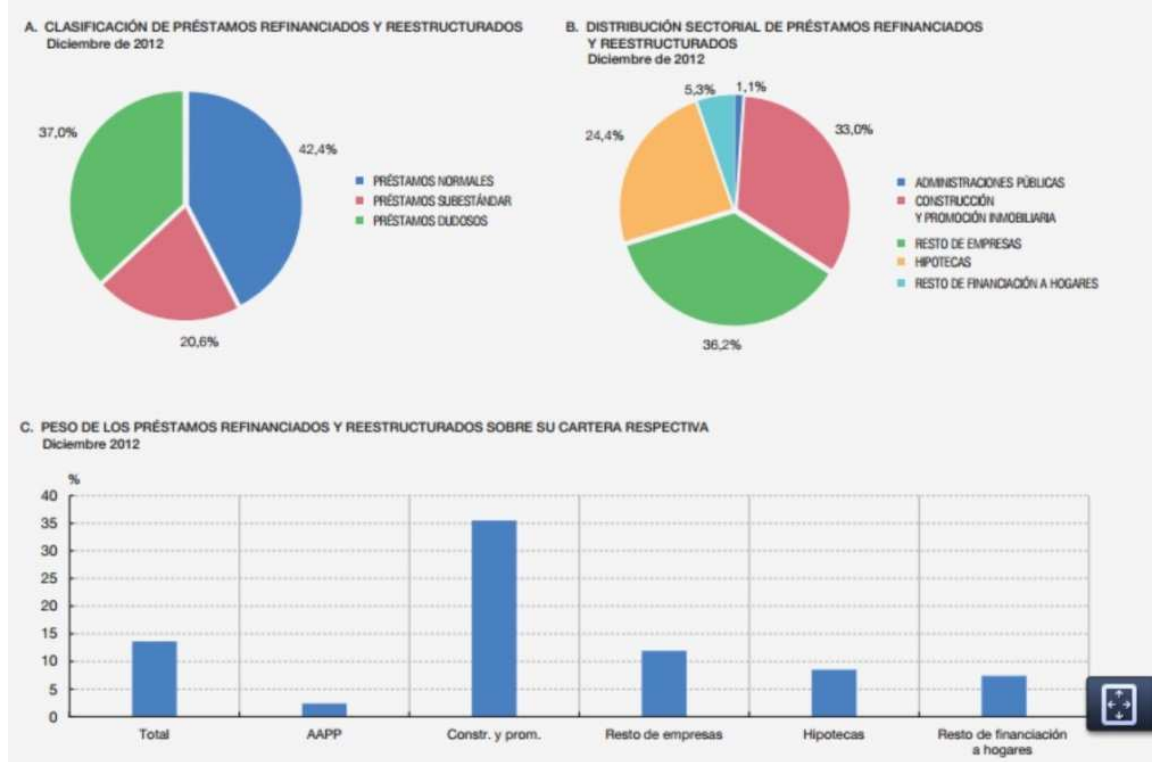

Fuente: BDE (VV.AA.): Boletín Económico; BDE (VV.AA.): Informe de estabilidad financiera. 
Alonso, Fernando y Blázquez, Pablo. Carry trade y credit crunch en la economía española.

CARGA FINANCIERA POR INTERESES Y RATIO DE DEUDA

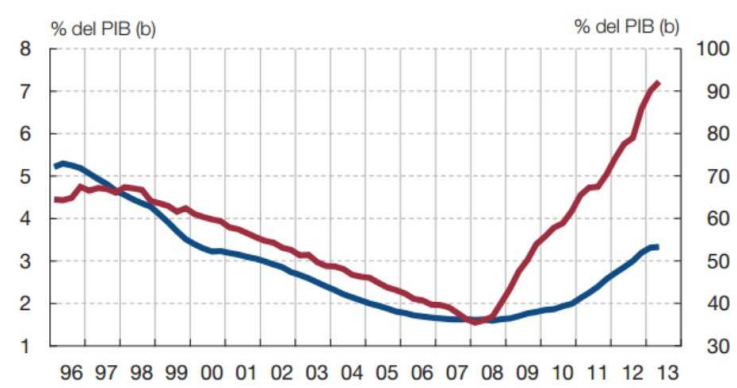

$$
\text { CARGA FINANCIERA }
$$

Fuente: BDE (VV.AA.): Boletín Económico; BDE (VV.AA.): Informe de estabilidad financiera.

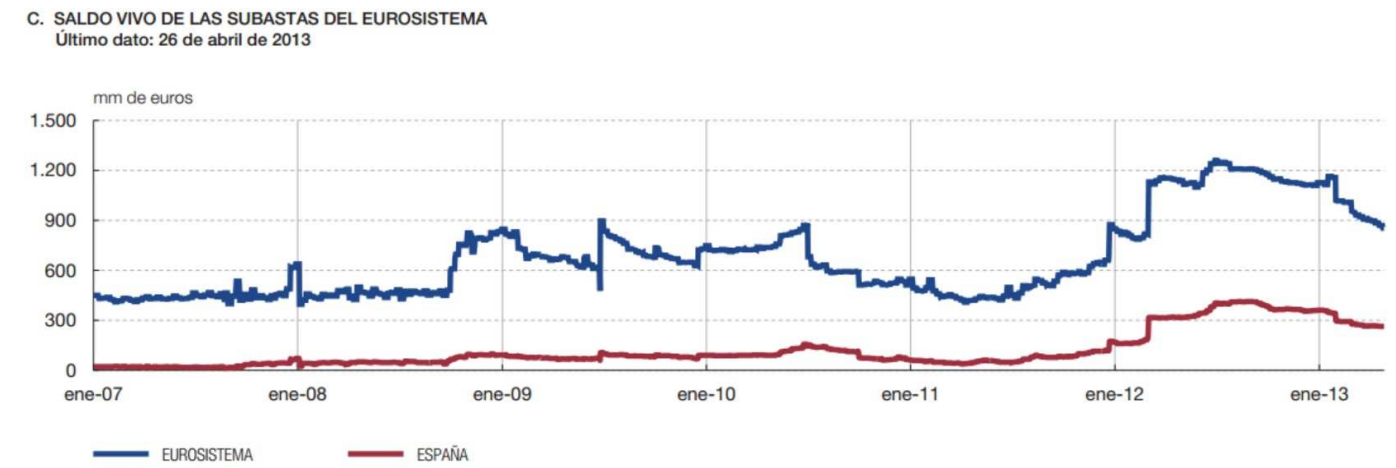

FUENTES: Bloomberg, Dealogic y Banco de España.

Fuente: BDE (VV.AA.): Boletín Económico; BDE (VV.AA.): Informe de estabilidad financiera.

Entidades de depósito, excepto grupos 1 y 2

GRÁFICO 2.16

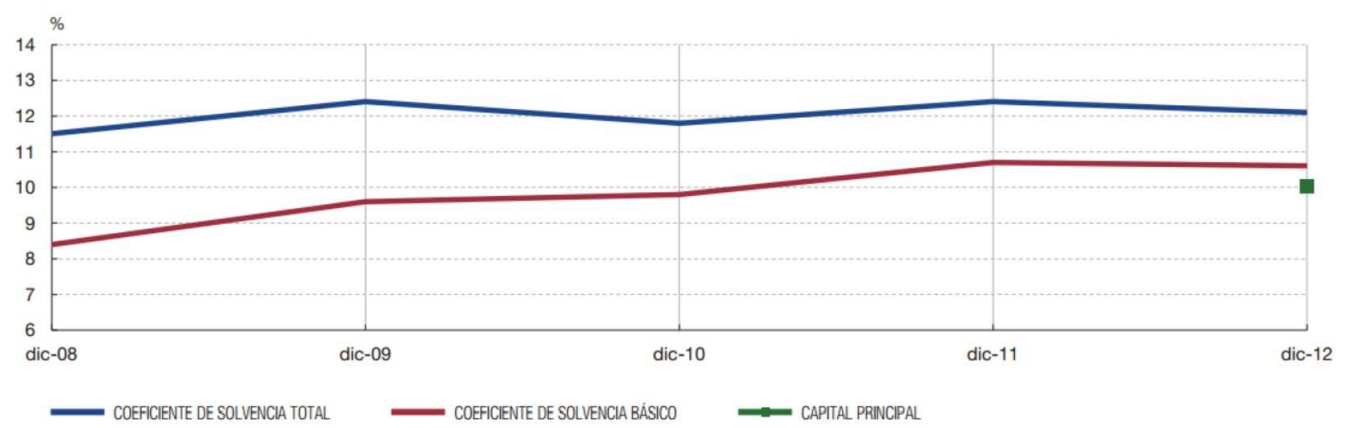

Fuente: BDE (VV.AA.): Boletín Económico; BDE (VV.AA.): Informe de estabilidad financiera. 